\title{
Inter-decadal changes in stratification and double diffusion in a transatlantic section along $7.5^{\circ} \mathrm{N}$
}

\author{
MIGUEL ÁNGEL SAN ANTOLÍN PLAZA ${ }^{1,2}$, JOSEP L. PELEGRÍ ${ }^{1,3}$, \\ FRANCISCO JOSÉ MACHÍN ${ }^{2}$ and VERÓNICA BENÍTEZ BARRIOS ${ }^{1}$ \\ ${ }^{1}$ Departament d'Oceanografia Física, Institut de Ciències del Mar, CSIC, Passeig Marítim de la Barceloneta 37-49, \\ 08003 Barcelona, Spain. E-mail: masa.plaza@icm.csic.es \\ ${ }^{2}$ Facultad de Ciencias del Mar, Universidad de Las Palmas G. C., Las Palmas, Spain. \\ ${ }^{3}$ LINCGlobal, CSIC-PUC, Facultad de Ciencias Biológicas, Pontificia Universidad Católica de Chile, Alameda 340, \\ Santiago, Chile.
}

SUMMARY: We use three transatlantic cruises (1957, 1993 and 2010) along $7.5^{\circ} \mathrm{N}$ to analyse inter-decadal variations of the neutral buoyancy frequency (with neutral density replacing potential density) and Turner angle. We also use Argo data from the 2003-2011 period to show that, within central and intermediate waters, the changes between the three sections are slightly greater than the seasonal and inter-annual variations, so they may be interpreted as actual inter-decadal variations. The results point to a generalized sinking of isoneutrals between 1957 and 2010, with maximum zonally-averaged values of about $100 \mathrm{~m}$ in the central and upper deep layers. They also reveal the occurrence of substantial changes in the intermediate and neighbouring water strata, with differential vertical sinking of isoneutrals and the transformation of their thermohaline characteristics. The neutral buoyancy frequency increased in the lower central and upper intermediate layers and decreased in the lower intermediate and upper deep layers. The distributions of Turner angle highlight a predominance of salt-fingering in the North Atlantic, except for a gravitationally doubly-stable layer located immediately below the intermediate water core; this stable layer thinned substantially between 1957 and 2010 because of the sinking of the lower intermediate isoneutrals acting together with actual water transformations from Antarctic Intermediate Waters into North Atlantic Deep Waters. We conclude that a significant portion of the water column underwent both increased vertical stratification and enhanced saltfingering, two mechanisms with opposite effects on the effective vertical diffusion.

Keywords: transatlantic section, stratification, neutral buoyancy frequency, Turner angle, inter-decadal changes, vertical diffusion.

RESUMEN: CAMBIOS INTERDECADALES EN ESTRATIFICACIÓN Y DOBLE DIFUSIÓN EN LA SECCIÓN TRANSATLÁNTICA 7.5²N. - USamos tres campañas transatlánticas $\left(1957,1993\right.$ y 2010) a lo largo de $7.5^{\circ} \mathrm{N}$ para analizar las variaciones interdecadales de la frecuencia de flotabilidad neutra (con la densidad neutra reemplazando a la densidad potencial) y el ángulo de Turner. También utilizamos datos Argo del periodo 2003-2011 para mostrar que, en las aguas centrales e intermedias, los cambios entre las tres secciones son algo superiores a las variaciones estacionales o interanuales, de modo que pueden interpretarse como cambios interdecadales. Los resultados indican un hundimiento generalizado de las isoneutras entre 1957 y 2010 , con valores máximos promediados zonalmente de unos $100 \mathrm{~m}$ en las aguas centrales y profundas superiores. También revelan la existencia de cambios substanciales en las aguas intermedias y los estratos vecinos, con desplazamientos verticales diferenciales de las distintas isoneutras, y la transformación de sus características termohalinas. La frecuencia de flotabilidad neutra aumentó en las capas centrales inferiores e intermedias superiores y disminuyó en las capas intermedias inferiores y profundas superiores. Las distribuciones del ángulo de Turner enfatizan la predominancia de dedos de sal en el Atlántico Norte, excepto en una capa gravitacionalmente estable ubicada inmediatamente por debajo del núcleo de aguas intermedias; esta capa estable se estrechó entre 1957 y 2010 debido al efecto conjunto del hundimiento de las isoneutras intermedias más profundas y la transformación de las Aguas Antárticas Intermedias en Aguas Noratlánticas Profundas. Concluimos que una porción significativa de la columna de agua experimentó tanto un aumento en la estratificación vertical como un incremento en el régimen de dedos de sal, dos mecanismos con efectos opuestos en la difusión vertical efectiva.

Palabras clave: sección trasatlántica, estratificación, frecuencia de flotabilidad neutra, ángulo de Turner, variaciones interdecadales, difusión vertical. 


\section{INTRODUCTION}

A North Atlantic tropical transect was carried out in May 1957 along $8.25^{\circ} \mathrm{N}$ by the R/V Crawford, as part of the International Geophysical Year (Fuglister 1960), and along $7.5^{\circ} \mathrm{N}$ in February-March 1993 by the R/V l'Atalante, within the World Ocean Circulation Experiment (Arhan et al. 1998). A transatlantic cruise in the equatorial North Atlantic took place in July 2000 but along a substantially different track (Lappo et al. 2001), so it is not considered in this analysis. In April-May 2010 the R/V Hespérides carried out the MOC2-Ecuatorial cruise to perform the third transatlantic section along $7.5^{\circ} \mathrm{N}$, obtaining a novel data set that has not yet been reported and/or discussed in peer-reviewed publications. The key importance of the $7.5^{\circ} \mathrm{N}$ section lies in the fact that it is a point of encounter of water masses of different origins, occupying different strata of the water column, with a substantial non-zero northward heat transport.

The meridional heat transport at $7.5^{\circ} \mathrm{N}$ in the Atlantic is about $0.7 \mathrm{PW}\left(1 \mathrm{PW}=10^{15}\right.$ Watts $)$ and it is maintained at similarly high levels as far as the northern North Atlantic Ocean (Ganachaud and Wunsch 2000). This heat transport depends on the vertical location of the water masses which, in turn, depends on the intensity of the Atlantic Meridional Overturning Circulation (AMOC). It is the AMOC that determines the amount of deep water formed at the northern (North Atlantic Deep Waters, NADW) and southern (Antarctic Bottom Waters, AABW) Atlantic boundaries as well as the intensity of the waters returning to the Northern Hemisphere to feed the NADW formation regions. These returning waters are Antarctic Intermediate Waters (AAIW) at intermediate depths and South Atlantic Central Waters (SACW) in the relatively shallow equatorial upper thermocline layers. The relatively warm SACW, with their origin as Antarctic mode waters which are highly transformed in the tropical and subtropical regions of the South Atlantic Ocean, are the main factor responsible for the large meridional net heat transport at $7.5^{\circ} \mathrm{N}$.

To a large extent the location of the water strata controls the processes responsible for vertical mixing; mixing, in turn, affects the extent of the strata. Some numerical results suggest that the intensity of the AMOC depends on the degree of vertical stratification which, in turn, affects the intensity of vertical mixing (Nilsson and Broström 2003, Marzeion and Leverman 2009). One key factor in this two-way interaction is double diffusion, as it effectively enhances vertical fluxes of properties in apparently stable waters (You et al. 2002, Ruddick 2003). In large regions of the global ocean, away from turbulent regions such as intense currents and near-boundary mixed layers, vertical mixing may indeed be controlled by the presence of double diffusion. Therefore, it is important to improve our knowledge on the way ocean vertical stratification and double diffusion may be evolving, especially in key locations such as the tropical Atlantic Ocean.
In this study we present the 2010 novel data set and focus on investigating how vertical stability and double diffusion have varied between all three cruises. The choice of adequate suitable common spatial grid is the first step to study potential changes in the variables and processes. Therefore, we begin by introducing the data set and explaining the interpolation and filtering techniques used when analysing the data in both depth and density reference systems. We turn next to the description of the two variables, Brunt-Väisälä (or buoyancy) frequency and Turner angle, used to analyse static stability and double diffusion processes; in particular, we propose and examine the behaviour of definitions that are slightly different to the classical ones, as they take into account water compressibility effects. This is followed by the presentation and discussion of the spatial distributions of buoyancy frequency and Turner angle. In particular, we use Argo data to show that the 2010 section is a good representative of the 2003-2011 conditions. This is followed by the central part of this study, in which the inter-decadal changes in the two variables are calculated and related to each other. The paper ends up with a summary of the observed trends and their implications.

\section{DATA SET}

The hydrographic data for the transatlantic nominal $7.5^{\circ} \mathrm{N}$ section were obtained during the cruises carried out in 1957, 1993 and 2010. The location of the stations for all three cruises is shown in Figure 1. Because each cruise followed a different path near South America, the inter-comparison region in this study extends only between $48.5^{\circ} \mathrm{W}$ and $15^{\circ} \mathrm{W}$, and the intense western boundary current system is therefore excluded.

The longitudinal resolution of the data was three times better in $1993\left(0.5^{\circ}\right)$ than in $1957\left(1.5^{\circ}\right)$. The vertical resolution was much lower in 1957 than in 1993, as the former data set was obtained with bottle water samples. Typically the 1957 data consisted of some 20 water bottles in the top $1000 \mathrm{~m}$ of the water column while the 1993 data was of one temperature and salinity value every metre. A detailed analysis of the 1957 and 1993 cruises has been reported elsewhere (Fuglister 1957, Arhan et al. 1998, Oudot et al. 1998, Marin and Gouriou 2000, Lux et al. 2001).

During the 2010 cruise the hydrographic stations had a spatial resolution of $0.5^{\circ}$ in the western Atlantic, as far as the Mid-Atlantic Ridge, and about $1^{\circ}$ on the eastern margin. The hydrographic stations included a conductivity-temperature-depth (CTD) probe that sampled the water column down to the sea bottom with vertical resolution of a few centimetres; the final files were constructed with a 1-m vertical resolution, as in the 1993 data set.

For the 1957 cruise the accuracy of salinity and temperature measurements was reported to be 0.01 and $0.1{ }^{\circ} \mathrm{C}$, respectively (Fuglister 1960). For the 1993 and 2010 cruises the salinity and temperature 


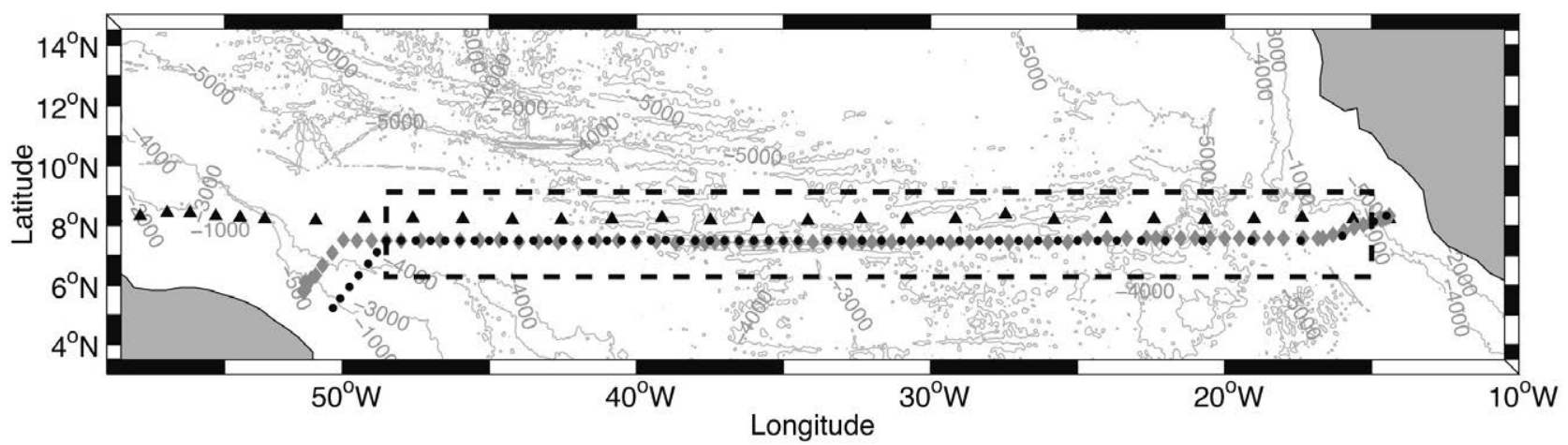

FIG. 1. - Stations for the IGFY 1957 (black triangles), WOCE A06 1993 (grey diamonds) and 2010 (black dots) transects. The intercomparison region, between $48.5^{\circ} \mathrm{W}$ and $15^{\circ} \mathrm{W}$, is shown. Isobaths are shown every $1000 \mathrm{~m}$.
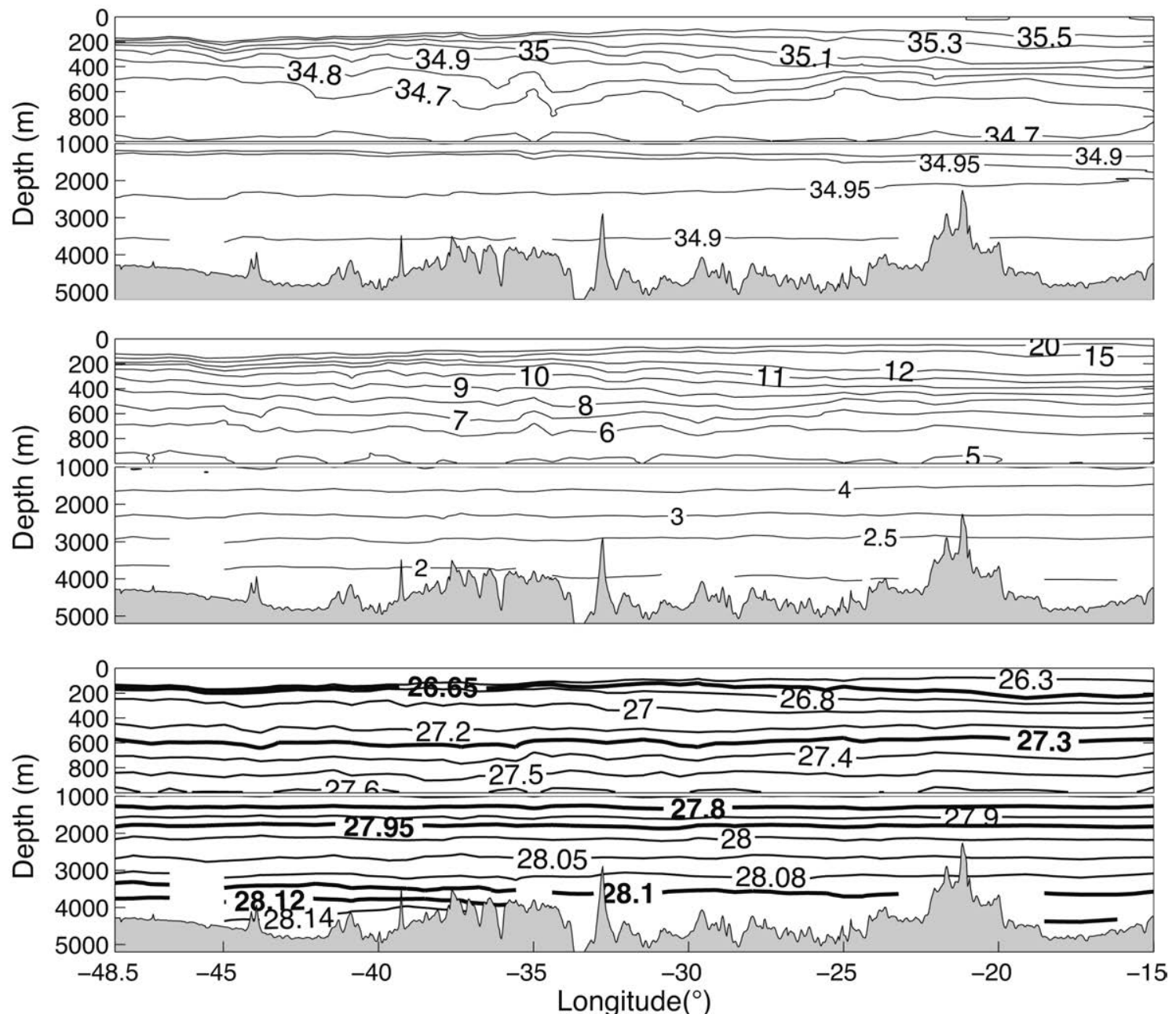

FIG. 2. - Distribution of (upper panel) potential temperature $\theta$, (middle panel) salinity $S$, and (lower panel) neutral density $\gamma^{n}$ for the 2010 transect. In the lower panel isoneutrals separating the distinct water masses $\left(\gamma^{n}=26.65,27.3,27.8\right.$ and 28.12$)$ and the upper, middle and lower deep waters $\left(\gamma^{n}=27.95,28.1\right)$ are shown as thicker black lines.

accuracy improved to 0.002 and $0.002^{\circ} \mathrm{C}$, respectively. Pressure accuracy also changed, as in 1957 it depended on the cable tilt (about $0.4 \%$ of the full range for a tilt of $5^{\circ}$, or $4 \mathrm{~m}$ in $1000 \mathrm{~m}$ water depth), while in the 1993 and 2010 studies it was of the order of $0.01 \%$ to $0.1 \%$ of the full pressure range ( 0.1 to 1 $\mathrm{m}$ in $1000 \mathrm{~m}$ water depth).

\section{WATER REGIONS AND WATER MASSES}

The distributions of potential temperature $(\theta)$, salinity $(S)$, and neutral density $\left(\gamma^{n}\right)$ for the 2010 cruise are depicted in Figure 2 as a function of depth and longitude. The gross patterns do not change substantially from those in the 1957 (Fuglister 1960) and 1993 


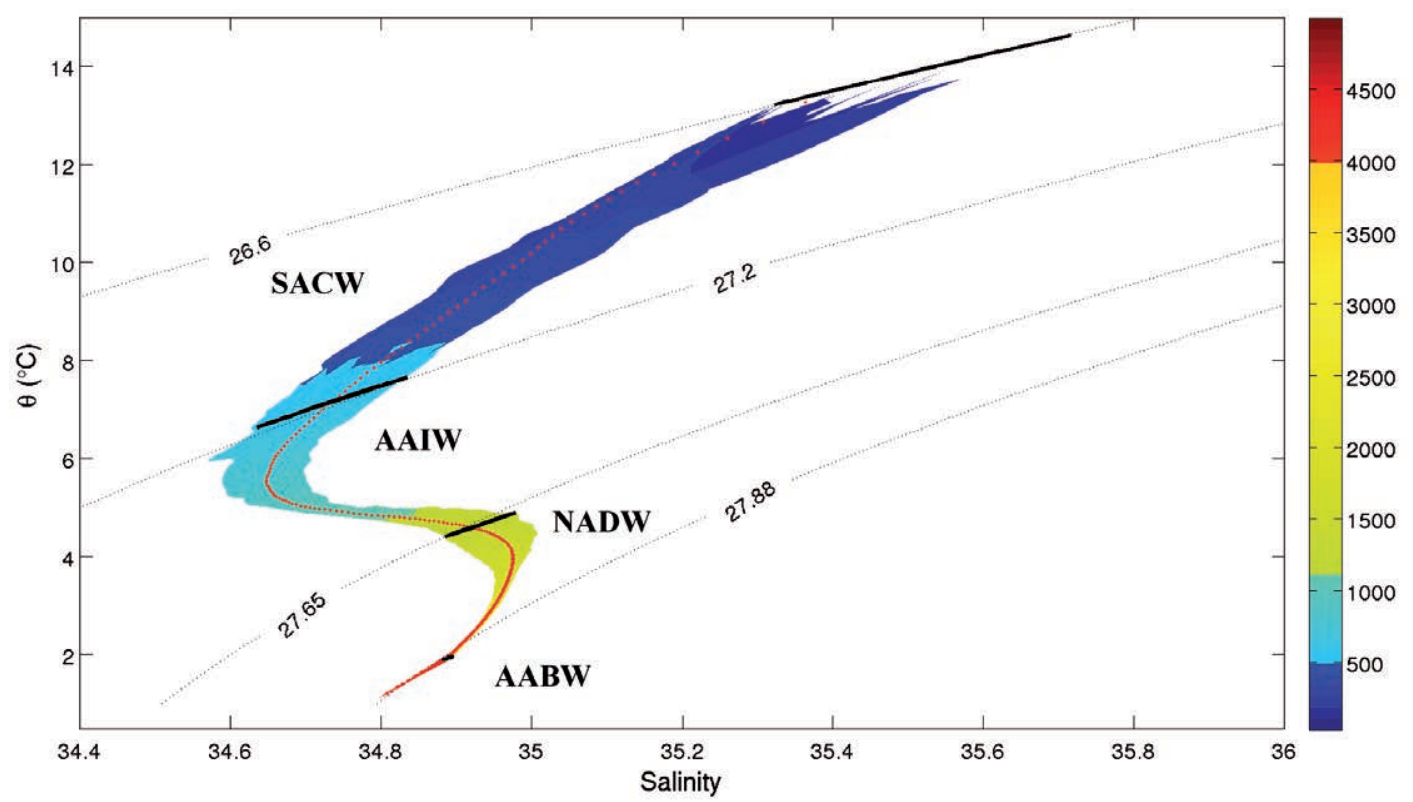

FIG. 3. - Potential temperature-salinity diagram, colour-coded for depth, as produced with data from the 2010 transect; a reference profile (dotted curve) is calculated as a zonal average for the different depth levels. The black dotted lines show several selected isopycnals $\left(\sigma_{\theta}=26.6\right.$,

$27.2,27.65,27.88)$ and the black curves correspond to isoneutrals separating the water masses $\left(\gamma^{n}=26.65,27.3,27.8\right.$ and 28.12). Waters lighter than $\gamma^{n}=26.65$ are excluded from this representation. A colour version of this figure may be found in the online electronic manuscript.

(Arhan et al. 1998) cruises, and may be used to divide the water column into depth-strata occupied by different water masses (Arhan et al. 1998): surface waters (down to $200 \mathrm{~m}$ ), central waters $(200-500 \mathrm{~m})$, intermediate waters (500-1100 m), deep waters (1100-4000 $\mathrm{m})$ and bottom waters $(>4000 \mathrm{~m})$. The deep waters are subdivided in three regions: upper deep waters (1100$1700 \mathrm{~m}$ ), middle deep waters (1700-3400 m) and lower deep waters (3400-4000 m).

Figure 2 zooms to the top $1000 \mathrm{~m}$ of the water column in order to provide a better view of the surface, central and intermediate waters. Two major features in the depth structure are the eastward deepening of the isotherms and isohalines within central waters, characteristic of the tropical cyclonic circulation (Stramma and Schott 1999, Schott et al. 2004), and the presence of relatively fresh and cold AAIW on the western margin, on its path from Antarctica to Equator along South America. Near the bottom we may also appreciate the presence of dense AABW on the western margin.

A depth-coded potential temperature-salinity diagram illustrates the correspondence of these properties with potential density and neutral density (Fig. $3)$. In this figure constant potential density anomaly $\sigma_{\theta}$ refers to sea surface pressure. In analogy to the notation for potential density anomaly, hereafter we use the notation $\gamma^{n}=$ value for a neutral density of $(1000+$ value $) \mathrm{kg} \mathrm{m}^{-3}$, and surfaces of constant $\gamma^{n}$ values are named isoneutrals. Neutral density was selected in this study (together with pressure) as the natural independent vertical variable to examine the changes in stratification and double diffusion, as it avoids the potential complications of having different reference pressures; for a thorough description of the concept of neutral density, see McDougall (1987) and Jackett and McDougall (1997). In Figure 3 several selected isoneutrals have been plotted on top of the data points; we may appreciate that isopycnals and isoneutrals are very similar at shallow depths but progressively differ from each other as the compressibility effects become important.

In Figure 3 we have also labelled the main participant water masses: surface waters (SW), SACW, AAIW, NADW and AABW. With the aid of this diagram, we may appreciate the approximate correspondence between the depth and neutral density domains occupied by the different water masses. Surface waters correspond to $\gamma^{n}<26.65$, central waters are within the $26.65<\gamma^{n}<27.3$ range, intermediate waters are within the $27.3<\gamma^{n}<27.8$ range, deep waters are within the $27.8<\gamma^{n}<28.12$ range, and bottom waters correspond to $\gamma^{n}>28.12$. The isoneutrals separating upper from middle deep waters and middle from lower deep waters are respectively found at $\gamma^{n}=27.95$ and 28.1 . Recall that isoneutrals, as they depend not only on potential temperature and salinity but also on pressure, may only be drawn over the cloud of data points; therefore, for the sake of clarity in Figure 3 we have also drawn several isopycnals that appear to closely match these selected isoneutrals.

\section{METHODS}

\section{Interpolation in pressure and neutral density}

The three data sets (1957, 1993 and 2010) have quite different spatial resolutions. Therefore, in order to enable the comparison and hence the study of the in- 
ter-decadal variability for the variables of interest, we have to construct a data mesh with equivalent vertical and horizontal resolution. In the vertical direction we do this in two different domains: depth and neutral density. The representation in these two domains provides, first, a complementary view of central intermediate and deep waters and, second, a more comprehensive understanding of the underlying physical processes. The first one is a practical advantage, as the neutral density domain expands the view of central and intermediate waters while the depth domain provides very high resolution of deep waters. The second, conceptual, advantage relies on the fact that changes of any variable $\phi$ at a given pressure level $p$ (or depth level $z$ ) may be decomposed as due to both heaving (sinking or raising of isoneutrals) and actual changes along isoneutral surfaces $\gamma^{n}$ (Bindoff and McDougall 1994), i.e.

$$
\left.\frac{d \phi}{d t}\right|_{p}=\left.\frac{d \phi}{d t}\right|_{\gamma^{n}}-\left.\frac{d p}{d t}\right|_{\gamma^{n}} \frac{\partial \phi}{\partial p} .
$$

The last term (heaving) is positive or negative depending on the sign of $\partial \phi / \partial p$, e.g. if $\partial \phi / \partial p<0$ this contribution is negative if the isoneutrals raise in time $\left(\partial p /\left.\partial t\right|_{y^{\prime}}<0\right)$. Alternatively, we may think of the neutraldensity representation as excluding heaving effects, so only changes arising from advection along isoneutral surfaces are included.

The first step is to carry out a vertical interpolation for every original station of the temperature and salinity data in both pressure and neutral density domains. To produce the mesh in the pressure domain the temperature and salinity fields are linearly interpolated to either 10 or $50 \mathrm{dbar}$, an interval suitable for investigating large-scale variability (these pressure intervals correspond, very closely, to 10 - or 50-m depth intervals; therefore, in the remaining of this paper we will talk indistinctly about the pressure or depth domains). The 50-dbar interpolated fields do not require any additional smoothing; the same is true of the fields interpolated at $10 \mathrm{dbar}$ for 1957 which, because of the sparse original vertical resolution, do not require any additional smoothing. In contrast, the 10-dbar interpolated 1993 and 2010 fields are further smoothed using a low-pass Butterworth filter of third order and 0.4 normalized frequency threshold. This process is carried out to minimize the number of small-scale overturns, of the order of $10 \mathrm{~m}$, preserving the information of the signal for longer vertical wavelengths. In this study the 10 dbar output is used to describe the distributions of the variables and their inter-decadal variations, while the 50 dbar output is used to examine the correlated changes between Turner angle and neutral buoyancy frequency.

To produce the mesh in the neutral density domain, the temperature and salinity fields are linearly interpolated to neutral density values with variable resolution. To describe the distributions of the variables the mesh employed changes from 0.02 at $\gamma^{n}=26.65$ to 0.005 in deep waters. Alternatively, to examine the correlated changes between the three cruises a coarser grid, increasing from 0.05 at $\gamma^{n}=26.65$ to 0.01 in deep waters, is used. No additional smoothing is necessary as the linear interpolation process ignores all data points where inversions are present, therefore producing salinity and temperature values that change monotonically with increasing density.

After the vertical interpolation, we carry out an interpolation in longitude. This process is equivalent for every cruise and domain, generating 58 interpolated stations between $48.5^{\circ} \mathrm{W}$ and $15^{\circ} \mathrm{W}$. Therefore, the longitudinal resolution of this interpolated grid is slightly better than $0.6^{\circ}$, or about $65 \mathrm{~km}$, which is suitable for investigating the large-scale ocean structure. Finally, the derived variables (density, neutral density, buoyancy frequency and Turner angle) are calculated directly and therefore have the same vertical and horizontal resolution as the interpolated temperature and salinity fields at each station. Throughout this work we will ignore the near-surface waters which are subject to seasonal variations, specifically waters shallower than $200 \mathrm{~m}$ or approximately lighter than $\gamma^{n}=26.65$.

\section{Buoyancy frequency}

Static stability may be examined with the aid of the buoyancy frequency, defined as

$$
N=\left(-\frac{g}{\rho_{\theta}} \frac{\partial \rho_{\theta}}{\partial z}\right)^{1 / 2},
$$

where $g$ is the gravity acceleration at every point of the water column, $\rho_{\theta}$ is the potential density calculated using a potential temperature $\theta$ referenced to the sea surface, and $z$ is depth. Positive values of the squared frequency involve stable stratification whereas negative ones correspond to unstable stratification.

A neutral buoyancy frequency, which uses neutral density instead of potential density, may be defined as follows:

$$
N_{n}=\left(-\frac{g}{\gamma^{n}} \frac{\partial \gamma^{n}}{\partial z}\right)^{1 / 2} .
$$

This new variable is expected to avoid the non-linear pressure-dependent effects in the potential density definition, which may cause artificial overturns and negative frequencies in regions far from the reference pressure level. A relative buoyancy-frequency difference is defined as follows:

$$
\Delta N^{2}=\frac{N^{2}-N_{n}^{2}}{N_{n}^{2}} .
$$

Despite the filtering in temperature and salinity in the depth domain (see previous subsection), a negative squared buoyancy frequency may occasionally appear for the 10-dbar interpolation with either 

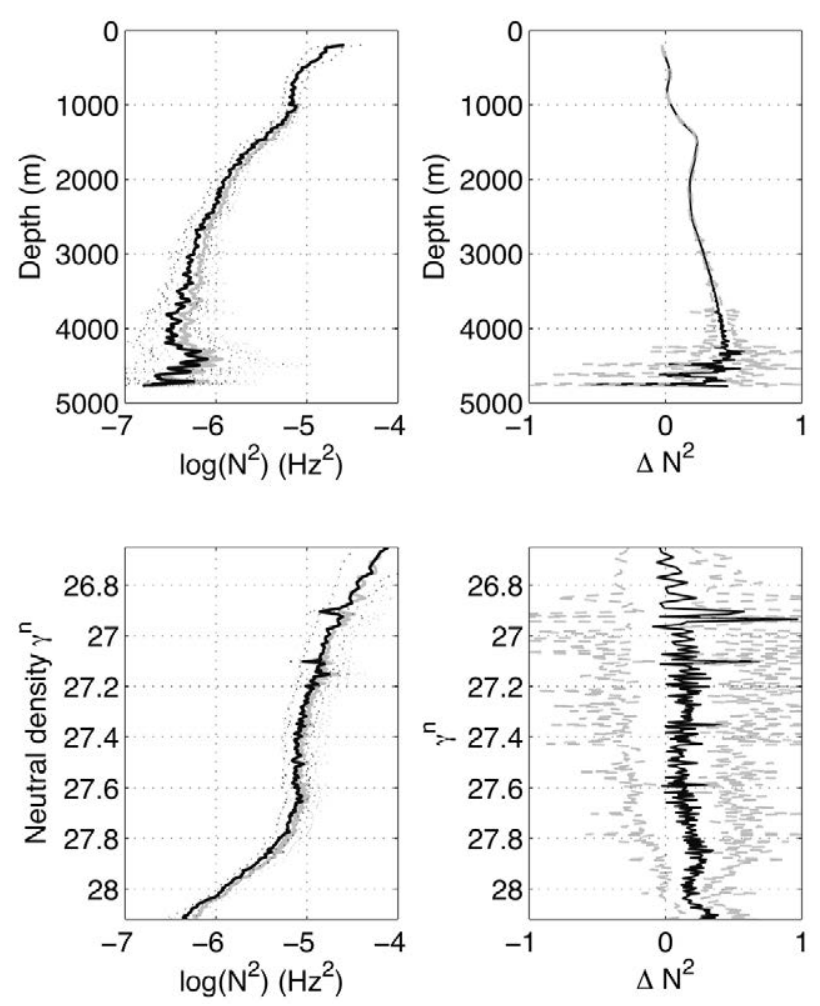

FIG. 4. - Comparison of the classical (Eq. 2) and modified (Eq. 3) buoyancy frequency distributions as obtained using the 2010 data set. The upper panels show the results in the depth domain and the lower panels show them in the neutral density domain. Left panels: mean profiles of $\log \left(N^{2}\right)$ (grey solid line) and $\log \left(N_{n}^{2}\right)$ (black solid line). Right panels: anomaly of relative squared buoyancy frequency as in Equation (4); the mean anomaly is plotted with a solid black line whereas the one-standard deviation intervals are dashed in grey.

Definition (2) or (3). These negative values are apparently caused by actual density overturns involving gravitational instabilities. In order to make possible the logarithmic representation of the squared buoyancy frequency distributions, we remove the density overturns following Thorpe (1977), i.e. the height of each overturn is determined and the density profile is smoothed before recalculating the buoyancy frequency.The vertical distributions of the buoyancy and neutral buoyancy frequencies are analysed in Figure 4 using the data from the 2010 cruise. In the depth domain, the zonally-averaged profiles are very similar in the top thousand metres of the water column but the differences increase with depth thereafter (upper left panel). In general, the buoyancy frequency is significantly higher than its neutral counterpart (notice the logarithmic scale for the $\mathrm{x}$-axis). This behaviour is also observed in the neutral density domain (lower left panel). However, in this case the differences between the two definitions remain significant down to intermediate waters $(27.8$ or $1100 \mathrm{~m})$. The standard deviations are quite similar for the two variables, although somewhat larger for the original $N^{2}$ definition; at deep levels the variability is significantly smaller for $N_{n}^{2}$ than for $N^{2}$, probably because using neutral density removes some of the non-linear effects in Equation (3).

The relative buoyancy-frequency difference helps to visualize the differences between the two definitions (Fig. 4). In the depth domain (upper right panel), both the zonally-averaged values and the standard deviations remain small for the top $1000 \mathrm{~m}$ and increase slowly with depth until about $4300 \mathrm{~m}$; below this level, i.e. within bottom waters, the zonally-averaged difference is reduced but the variability increases. When plotted in the neutral density domain (lower right panel), the zonallyaveraged values remain low at all density levels and the one-standard deviation intervals are substantially larger than in the depth domain, except for the lower deep and bottom waters ( $\gamma^{n}>28.1$ or about $3400 \mathrm{~m}$ ).

On the basis of these results, though the two buoyancy frequency definitions display only few differences in most of the water column, we adopt the definition of neutral buoyancy frequency (Eq. 3) for the remaining calculations throughout this paper.

\section{Turner angle}

The Turner angle is used to assess the static stability of a water parcel as a result of potential buoyancy changes associated with double-diffusive mixing processes. It is defined as (Ruddick 1983):

$$
T u=\tan ^{-1}\left(\frac{\alpha \Delta \theta-\beta \Delta S}{\alpha \Delta \theta+\beta \Delta S}\right)
$$

where $\alpha=-(1 / \rho) \partial \rho / \partial \theta$ is the thermal expansion coefficient and $\beta=(1 / \rho) \partial \rho / \partial S$ is the haline contraction coefficient of seawater, with $\rho$ being in situ density. The Turner angle characterizes several regimes with different stability conditions. For $|T u|<45^{\circ}$ the water column is stable in terms of $\partial \theta / \partial z$ (positive gradient) and $\partial S / \partial z$ (negative gradient); double diffusion occurs for $45^{\circ}<|T u|<90^{\circ}$, specifically the salt-finger regime prevails for $45^{\circ}<T u<90^{\circ}$ while the diffusive regime occurs for $-90^{\circ}<T u<-45^{\circ}$; finally, $|T u|>90^{\circ}$ involves gravitational instabilities.

We may define a variable analogous to the Turner angle, but using a moving reference level for the potential temperature instead of referring it to a zero pressure level. Since the Turner angle is calculated using temperature differences between two points separated in the vertical, the natural reference pressure is the intermediate position between these two points. As for the neutral buoyancy frequency, the objective here is to remove any possible artefacts caused by having a distant reference level. We denote this potential temperature by $\theta_{p}$, and the corresponding thermal expansion and haline contraction coefficients as $\alpha_{p}$ and $\beta_{p}$. The corresponding Turner angle definition is:

$$
T u_{P}=\tan ^{-1}\left(\frac{\alpha_{P} \Delta \theta_{P}-\beta_{P} \Delta S}{\alpha_{P} \Delta \theta_{P}+\beta_{P} \Delta S}\right) .
$$



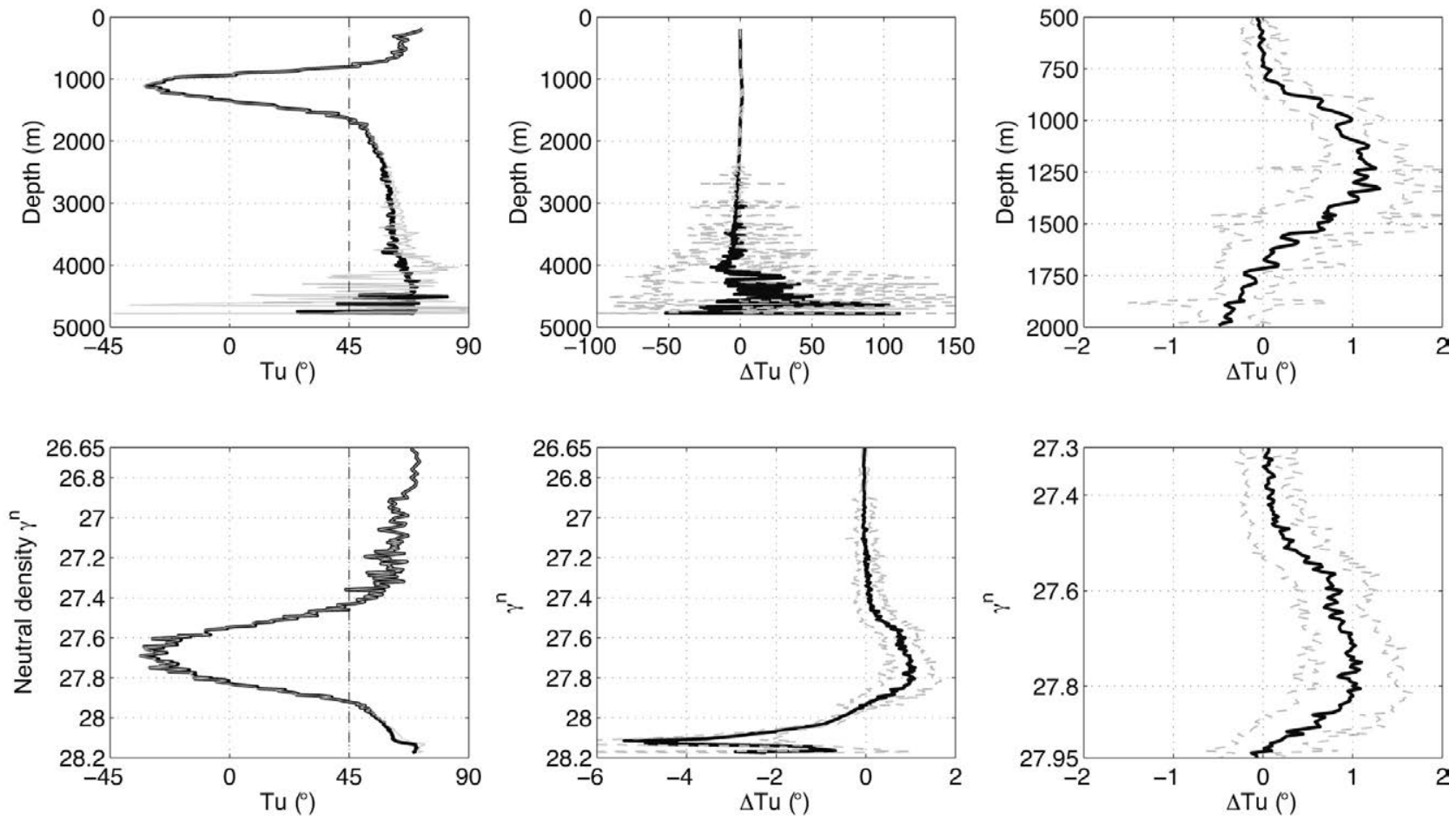

FIG. 5. - Comparison of the classical (Eq. 5) and modified (Eq. 6) Turner angle distributions as obtained using the 2010 data set. The upper panels show the results in the depth domain and the lower panels show them in the neutral density domain. Left panels: mean profiles of $T u$ (black solid line) and $T u_{\mathrm{p}}$ (grey solid line). Middle panels: Turner angle difference according to Equation (7); the mean difference is plotted with a solid black line whereas the one-standard deviation intervals are dashed in grey. Right panels: as in the middle panels but zooming at the intermediate levels.

The absolute difference between Definitions (5) and (6) is given by:

$$
\Delta T u=T u-T u_{P} .
$$

The results from Definitions (5) and (6), calculated using the data from the 2010 cruise, are plotted as a function of both depth and neutral density (Fig. 5). The left panels show the zonally-averaged Turner values while the middle and right panels plot the absolute difference values. In the middle and right panels the one-standard deviation intervals are also shown. In the depth domain (upper panels) the difference between the zonally-averaged values remains negligible until about $2000 \mathrm{~m}$ but becomes substantial below about $3000 \mathrm{~m}$. The original definition displays much less variability for deep and bottom waters. The differences are much smaller when calculated in the neutral density domain (lower panels). The two definitions practically overlap (lower left panel), with much smaller differences than for the depth domain (lower middle and right panels). In this domain the differences remain within a few degrees, the sign changing from positive at intermediate and upper deep waters $\left(27.3<\gamma^{n}<27.95\right)$ to negative at middle and lower deep waters $\left(\gamma^{n}>27.95\right)$. Hereafter, we will use the original Definition (5) to map the Turner angle distributions, as it substantially reduces the variability of the signal when calculated in the depth domain for waters below $3000 \mathrm{~m}$.

\section{BUOYANCY FREQUENCY AND TURNER ANGLE DISTRIBUTIONS}

We now present the distributions of the neutral buoyancy frequency (Fig. 6) and the Turner angle (Fig. 7) for all three cruises, as a function of both depth and neutral density, and briefly discuss the most important features. Figure 6 illustrates that, below the surface mixed layer and seasonal thermocline, the fundamental characteristic is a generalized increase in static stability with depth. However, the plots in the density domain (see also Fig. 4) indicate the presence of several local maxima, particularly in the intermediate water range. All three sections share the same gross characteristics, although the stratification of intermediate waters on the western margin appears to have increased slightly with time. We will come back later to this issue when calculating the actual temporal changes in the neutral buoyancy frequency.

An important feature present in all sections is the zonal asymmetry of central waters. Immediately below the seasonal thermocline the western margin appears more stratified than the eastern margin but the situation reverses in the central and intermediate waters, with more stratified waters in the eastern half of the basin (see also Fig. 2). This asymmetry reflects the presence of different water masses and the existence of different dynamic processes. On the western margin the relatively fresh AAIW is most abundant (e.g. Lozier 

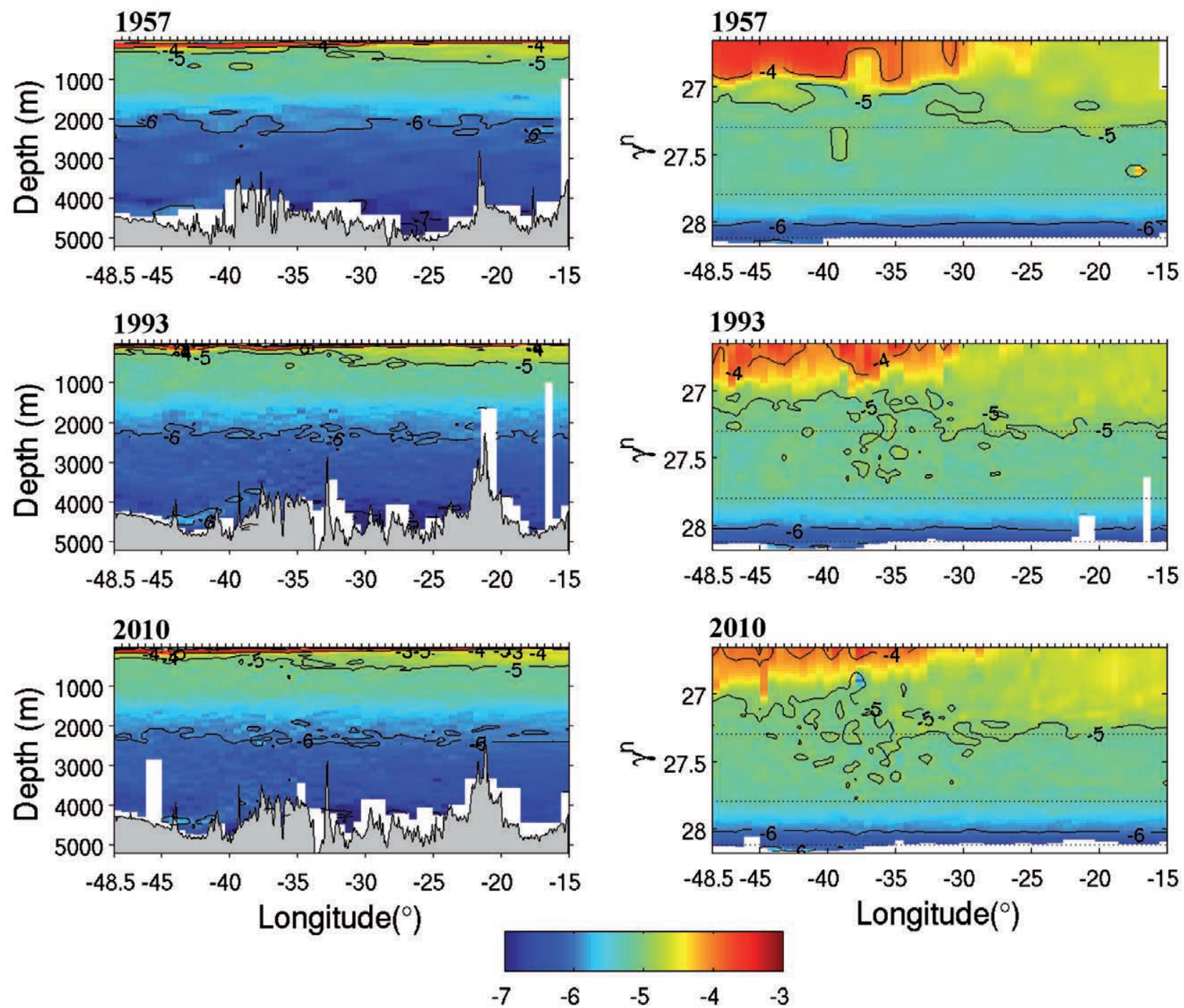

FIG. 6. - Distribution of neutral buoyancy frequency, $\log \left(N_{n}^{2}\right)$, for the 1957 (upper panels), 1993 (middle panels), and 2010 (lower panels) data sets. Left panels are depicted in the depth domain whereas right panels use the neutral density domain. The horizontal dotted lines in the density domain represent the main boundaries between central, intermediate, deep and bottom waters $\left(\gamma^{n}=27.3,27.8\right.$ and 28.12$)$. A colour version of this figure may be found in the online electronic manuscript.

et al. 1995), leading to a decrease in stratification at the SACW-AAIW boundary. In the eastern basin the central water isopycnals become more tightly packed in response to the cyclonic circulation within the subtropical cells (Schott et al. 2004). Finally, the appearance of AABW at the deepest western corner is detectable through slightly higher frequency values (Arhan et al. 1998). We observe that the characteristic values for $N_{n}^{2}$ range between $10^{-4}$ and $10^{-6} \mathrm{~s}^{-2}$, which means $N_{n}$ values between $10^{-2}$ and $10^{-3} \mathrm{~s}^{-1}$. Therefore, water parcels have natural vertical oscillations with periods that range from one minute to an hour.

In order to examine the presence of double-diffusive mixing processes in the water column, we look at the distributions of the Turner angle for all three cruises as a function of both depth and neutral density (Fig. 7). You (2002) presented a Turner angle atlas for the Atlantic Ocean, including the vertical distribu- tion in a meridional section along $30^{\circ} \mathrm{W}$. You (2002) emphasized the existence of a complex structure with predominance of salt-fingering conditions. Our results indeed confirm the predominance of salt-fingering conditions, although there is only a relatively small region in the western margin that displays strong-fingering $\left(T u>75^{\circ}\right)$ conditions. Schmitt et al. $(1987,2005)$ found strong staircases in an extensive area northwest of $\left(7.5^{\circ} \mathrm{N}, 48.5^{\circ} \mathrm{W}\right)$, off the western end of our $7.5^{\circ} \mathrm{N}$ section. However, from Figure 7 we find that strong salt-fingering appears only as small-scale patches in central waters, indicating that the $7.5^{\circ} \mathrm{N}$ transatlantic equatorial region is not generally prone to intense double diffusion processes.

The dominance of salt-fingering may be understood from the typical shapes of the potential temperature and salinity profiles (Fig. 3). Temperature increases monotonically from the surface mixed layer to the sea bottom, 

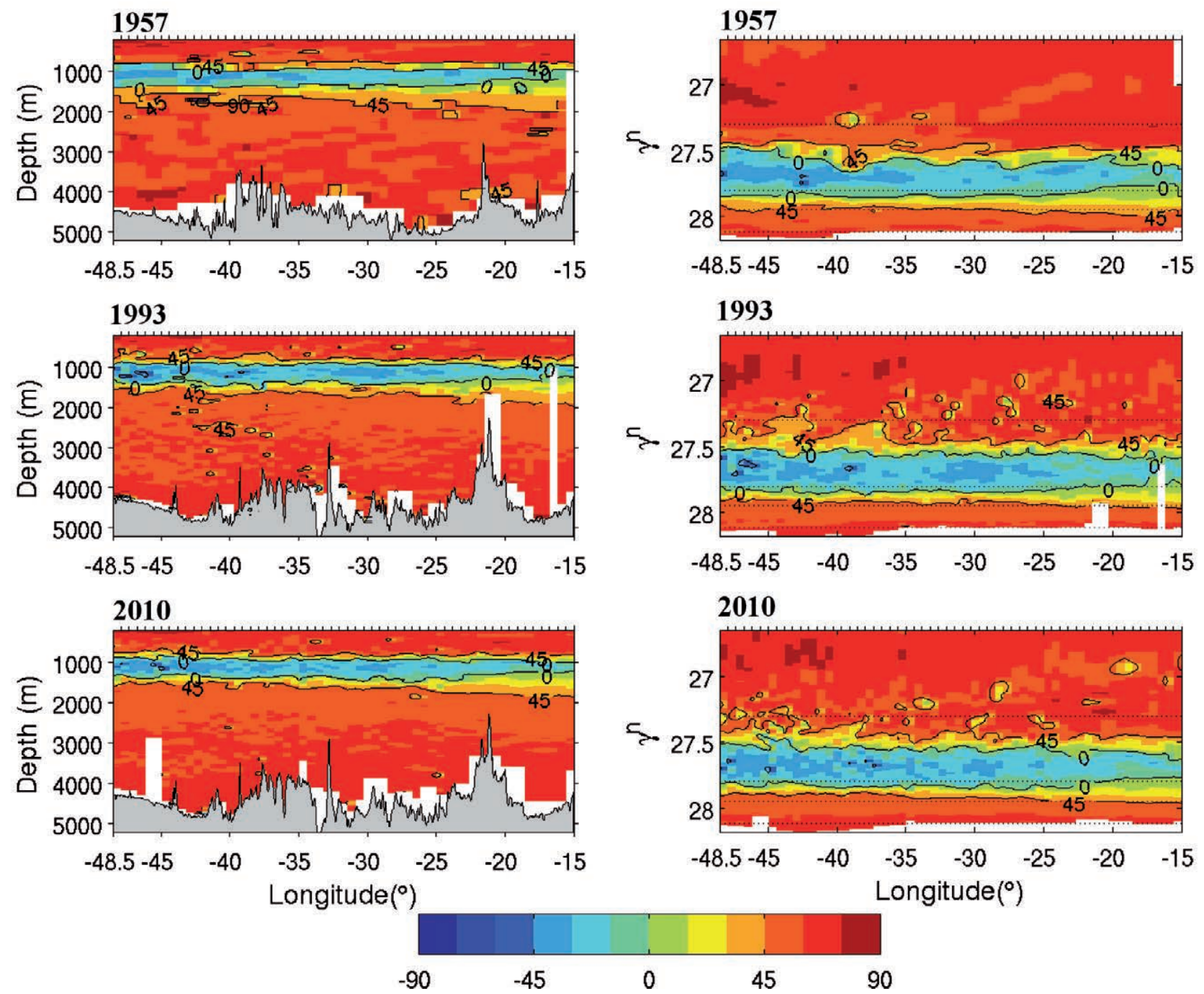

FIG. 7. - Distribution of Turner angle, Tu, for the 1957 (upper panels), 1993 (middle panels), and 2010 (lower panels) data sets. Left panels are depicted in the depth domain whereas right panels use the neutral density domain. The three colour tones for diffusive convection and salt-fingering refer to weak, medium and strong double diffusion; the darker the tone, the more intense the process. The horizontal dotted lines in the density domain represent the main boundaries between central, intermediate, deep and bottom waters $\left(\gamma^{n}=27.3,27.8\right.$ and 28.12$)$; the limit between upper and middle deep waters $\left(\gamma^{n}=27.95\right)$ is also shown.

providing stability to the water column (generalized positive gradient). On the other hand, salinity exhibits a non-monotonic behaviour, decreasing from the surface mixed layer down to approximately $800 \mathrm{~m}$ depth, then increasing to depths of between 1500 and $2000 \mathrm{~m}$, and decreasing again at greater depths. Those regions where positive vertical salinity gradients are able to overcome the stabilization effect of the positive vertical temperature gradients have the potential to give rise to salt-fingering. The existence of the different regimes is therefore determined by the encountering of salty central and deep waters of northern origin with relatively fresh intermediate and bottom waters of southern origin.

Another noteworthy feature along $7.5^{\circ} \mathrm{N}$ is the presence of a band of doubly-stable water (where both temperature and salinity gradients are stable) associated with the intrusion of the relatively fresh and cold
AAIW. This band is located between the core of AAIW and the upper portion of NADW, typically between about 800 and 1600-2000 $\mathrm{m}$ in the depth domain (widening eastwards) or between about 27.5 and 27.9 in the neutral density domain. The extent of the gravitationally stable $T u$ layer is related to the location of the intermediate and upper deep waters in the $\gamma^{n}$ domain (right panels of Fig. 7). The lower limit of the gravitationally stable layer rose with time: in 1957 this boundary roughly coincided with the 27.95 isoneutral while in 1993 and 2010 it was well above it, ascending slightly from 1993 to 2010. The conclusion is that waters with neutral density between 27.9 and 27.95 experienced a transition from AAIW towards NADW conditions. On the other hand, the evolution of the upper limit is less well defined, also suggesting a small increase in the extent of the salt-fingering region but with a patchier 

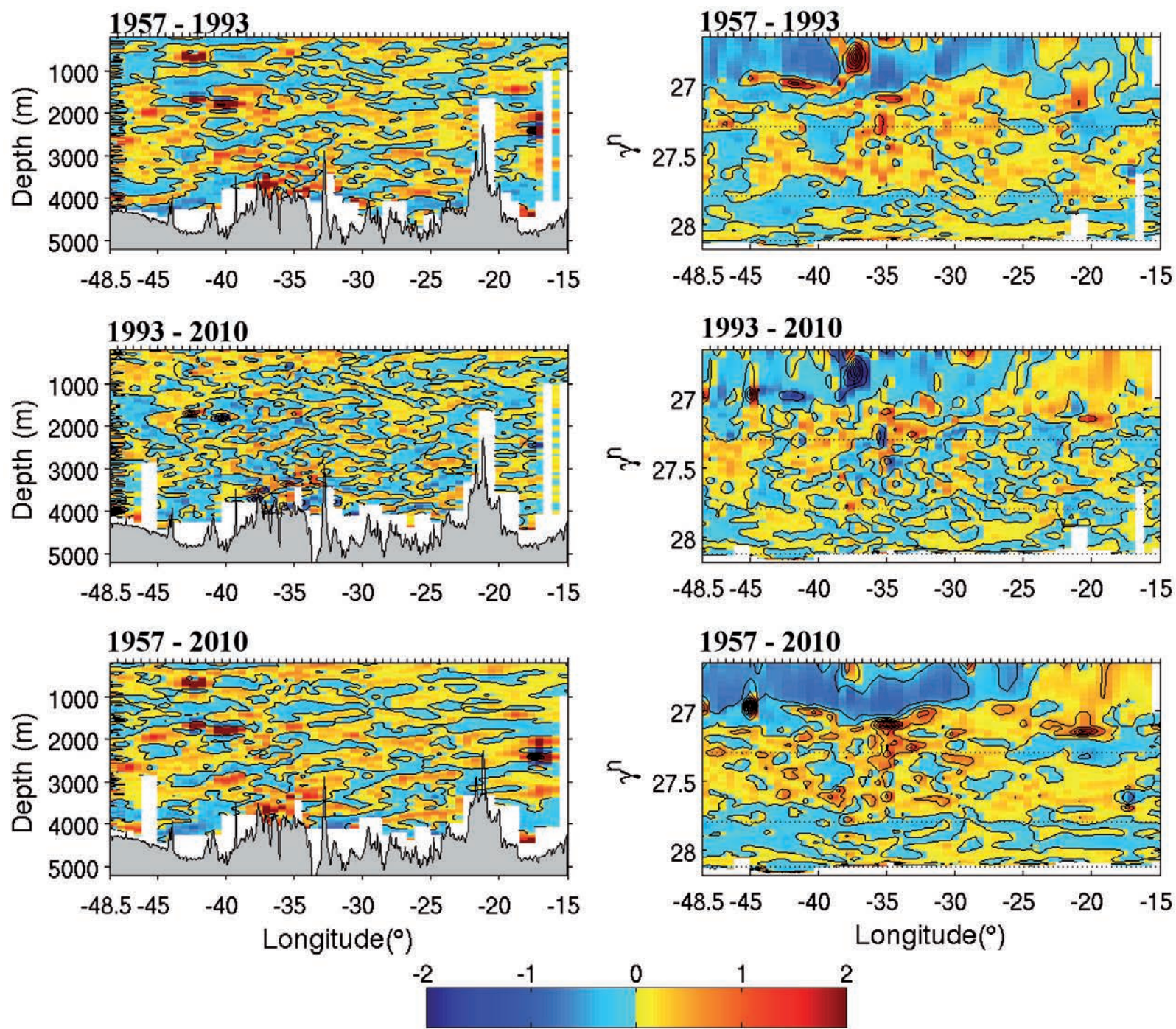

FIG. 8. - Relative temporal variation of the squared neutral buoyancy frequency, $\Delta N_{n}{ }^{2}$ (Eq. 8), for the depth (left) and neutral density (right) domains; the upper, middle and lower panels respectively indicate changes for the periods 1957-1993, 1993-2010 and 1957-2010. Increases in stratification appear in warm colours, decreases in cold colours.

signal. Finally, it is worth mentioning that diffusive convection was absent in 1957 but appeared in 1993 and 2010 as isolated small-scale patches in the western part at the intermediate deep waters interface, when the temperature gradients locally revert in otherwise doubly-stable waters.

In the following section we will look at the temporal changes in our two principal variables, $N_{n}$ and $T u$, and examine the way in which they are related. We may anticipate, for example, that an increased presence of upper NADW could lead to basin-wide salinity changes and, therefore, to associated changes in double-diffusive processes. To this end, we first examine the size of the changes in neutral buoyancy frequency and Turner angle between all three sections, then make a succinct analysis on whether these differences are really representative of inter-decadal changes, and end up looking at how the changes in $N_{n}$ and $T u$ are connected.

\section{INTER-DECADAL CHANGES}

\section{Distributions of temporal changes}

In order to examine the temporal changes in neutral buoyancy frequency we use a relative quantity, analogous to Equation (4). The relative temporal variability of the squared neutral buoyancy frequency is defined as:

$$
\Delta N_{n}^{2}=\frac{N_{n f}^{2}-N_{n i}^{2}}{N_{n 57}^{2}}
$$

where the subindexes $f$ and $i$ respectively denote the final and initial state and $N_{n 57}^{2}$ corresponds to the value of this variable for the 1957 section, which is taken as a reference.

Figure 8 shows the maps for $\Delta N_{n}^{2}$ as calculated between the different repetitions (1957-1993, 1993-2010 
TABLE 1. - Integrated values of the relative temporal variation of the squared neutral buoyancy frequency, $\Delta N_{n}^{2}$ (Eq. 8), for different regions of the water column in both the depth and density domains. The water masses in the depth domain are specified as follows: CW, central waters (200-500 m); IW, intermediate waters (500-1100 m); UDW, upper deep waters (1100-1700 m); MDW, middle deep waters (1700-3400 m); LDW, lower deep waters (3400-4000 m); BW, bottom waters (below $4000 \mathrm{~m}$ ). The water masses in the density domain are specified as follows: CW, (26.7-27.3); IW, (27.3-27.8); UDW, (27.8-27.95); MDW, (27.95-28.1); LDW, (28.1-28.12); BW, (>28.12).

\begin{tabular}{cccccccc}
\hline & & CW & IW & UDW & MDW & LDW & BW \\
\hline$p$ domain & $1957-1993$ & $0.03 \pm 0.05$ & $0.03 \pm 0.03$ & $0.02 \pm 0.09$ & $0.13 \pm 0.08$ & $0.12 \pm 0.08$ & $0.07 \pm 0.37$ \\
& $1993-2010$ & $0.12 \pm 0.05$ & $0.04 \pm 0.02$ & $0.00 \pm 0.02$ & $0.00 \pm 0.04$ & $-0.05 \pm 0.09$ & $0.10 \pm 0.23$ \\
& $1957-2010$ & $0.15 \pm 0.05$ & $0.07 \pm 0.03$ & $0.02 \pm 0.08$ & $0.14 \pm 0.08$ & $0.09 \pm 0.10$ & $0.21 \pm 0.64$ \\
$\gamma^{n}$ domain & & & & & & & \\
& $1957-1993$ & $0.05 \pm 0.13$ & $0.10 \pm 0.06$ & $-0.06 \pm 0.02$ & $0.04 \pm 0.05$ & $0.05 \pm 0.18$ & $0.07 \pm 0.12$ \\
& $1993-2010$ & $0.02 \pm 0.10$ & $0.03 \pm 0.03$ & $0.00 \pm 0.02$ & $0.00 \pm 0.02$ & $-0.08 \pm 0.02$ & $0.13 \pm 0.23$ \\
& $1957-2010$ & $0.07 \pm 0.23$ & $0.13 \pm 0.07$ & $-0.06 \pm 0.04$ & $0.04 \pm 0.06$ & $0.01 \pm 0.19$ & $0.21 \pm 0.31$ \\
\hline
\end{tabular}

and 1957-2010), plotted as a function of depth and neutral density. Intense patchiness is the most obvious feature in these maps, possibly caused by processes not resolved in the sampling. One such process is internal waves that may cause the water parcels to become displaced by vertical distances of the order of $100 \mathrm{~m}$; these displacements do not change the water mass properties but do locally affect the buoyancy frequency. Another predominant feature is a marked asymmetry between the western and eastern basins, most noticeable in central waters when plotted in the neutral density domain (right panels of Fig. 8).

In order to better understand how the buoyancy frequency distribution has changed in the last 53 years, we also calculated the integrated mean values for every region of the water column in both the depth and neutral-density domains (Table 1). We may expect, for example, that internal waves shall not affect this integrated frequency. In the density domain, $N_{n}{ }^{2}$ only increases significantly (mean value greater than the standard deviation) in intermediate waters while there is a noticeable decrease in upper deep waters (19571993 and 1957-2010 periods) and lower deep waters (1993-2010 period). Central waters also exhibit an increase during all three periods, but with standard deviations larger than the mean values. In the depth domain, the only significant changes in $N_{n}^{2}$ are an increase for central and intermediate waters during the 1993-2010 and 1957-2010 periods, and an increase for the middle deep waters during the 1957-2010 period.

These results suggest that temporal changes of $N_{n}{ }^{2}$ at intermediate levels have a positive contribution due to actual changes in the water characteristics and a negative contribution due to the heaving term; recall Equation (1) and notice that $\partial N^{2} / \partial p$ is generally negative in the ocean except in central intermediate waters (Fig. 4) so the heaving term also implies sinking isoneutrals. The negative heaving contribution is smaller than the positive contribution in the neutraldensity domain, so the resulting change in the depth domain is positive and still significant. The results also indicate that both deep and central waters have experienced a substantial increase in stratification, mainly related to a positive heaving contribution, therefore pointing at a generalized sinking of isoneutrals within these water strata.

In order to examine whether the stratification changes were different in the western and eastern basins, we divided the transatlantic section at $34^{\circ} \mathrm{W}$, near the centre of the Mid-Atlantic Ridge (Fig. 1); the western and eastern basins thus cover 25 and 33 interpolated stations, respectively. The temporal variations in $\Delta N_{n}^{2}$ exhibit relevant differences between the western and eastern basins in both domains (Table 2). The largest differences are observed for central waters, particularly in the neutral-density domain, reflecting an increase in stratification in the eastern basin because of changes in water mass composition and a positive heaving contribution (sinking of isoneutrals) in both basins.

The changes in water mass characteristics and the sinking/rising of isoneutrals may cause temporal transitions in the double-diffusive character of the water column. We may examine the presence of such changes through temporal variations in the Turner angle, a relation equivalent to Equation (7) but now with temporal changes,

$$
\Delta T u=T u_{f}-T u_{i},
$$

TABLE 2. - Integrated values of the relative temporal variation of the squared neutral buoyancy frequency, $\Delta N_{n}^{2}$ (Eq. 8), for both the eastern and western Atlantic basins (east and west $34^{\circ} \mathrm{W}$ ). Values for central, intermediate and upper deep waters are shown for both the depth and neutral density domains.

\begin{tabular}{|c|c|c|c|c|c|c|c|}
\hline & & \multicolumn{3}{|c|}{ Western basin $\left(48.5-34^{\circ} \mathrm{W}\right)$} & \multicolumn{3}{|c|}{ Eastern basin $\left(34-15^{\circ} \mathrm{W}\right)$} \\
\hline & & $\mathrm{CW}$ & IW & UDW & $\mathrm{CW}$ & IW & UDW \\
\hline \multirow[t]{3}{*}{$p$ domain } & $1957-1993$ & $-0.04 \pm 0.13$ & $0.02 \pm 0.08$ & $0.00 \pm 0.14$ & $0.09 \pm 0.08$ & $0.04 \pm 0.04$ & $0.04 \pm 0.07$ \\
\hline & $1993-2010$ & $0.15 \pm 0.05$ & $0.07 \pm 0.03$ & $-0.02 \pm 0.09$ & $0.09 \pm 0.06$ & $0.01 \pm 0.03$ & $0.00 \pm 0.05$ \\
\hline & $1957-2010$ & $0.12 \pm 0.16$ & $0.10 \pm 0.07$ & $-0.02 \pm 0.07$ & $0.17 \pm 0.08$ & $0.05 \pm 0.05$ & $0.04 \pm 0.09$ \\
\hline \multirow[t]{3}{*}{$\gamma^{n}$ domain } & $1957-1993$ & $0.05 \pm 0.15$ & $0.09 \pm 0.12$ & $-0.11 \pm 0.07$ & $0.05 \pm 0.14$ & $0.11 \pm 0.03$ & $-0.02 \pm 0.05$ \\
\hline & $1993-2010$ & $-0.04 \pm 0.20$ & $0.06 \pm 0.06$ & $0.01 \pm 0.02$ & $0.06 \pm 0.07$ & $0.01 \pm 0.05$ & $-0.01 \pm 0.04$ \\
\hline & $1957-2010$ & $0.01 \pm 0.34$ & $0.16 \pm 0.11$ & $-0.10 \pm 0.06$ & $0.12 \pm 0.19$ & $0.11 \pm 0.06$ & $-0.04 \pm 0.05$ \\
\hline
\end{tabular}



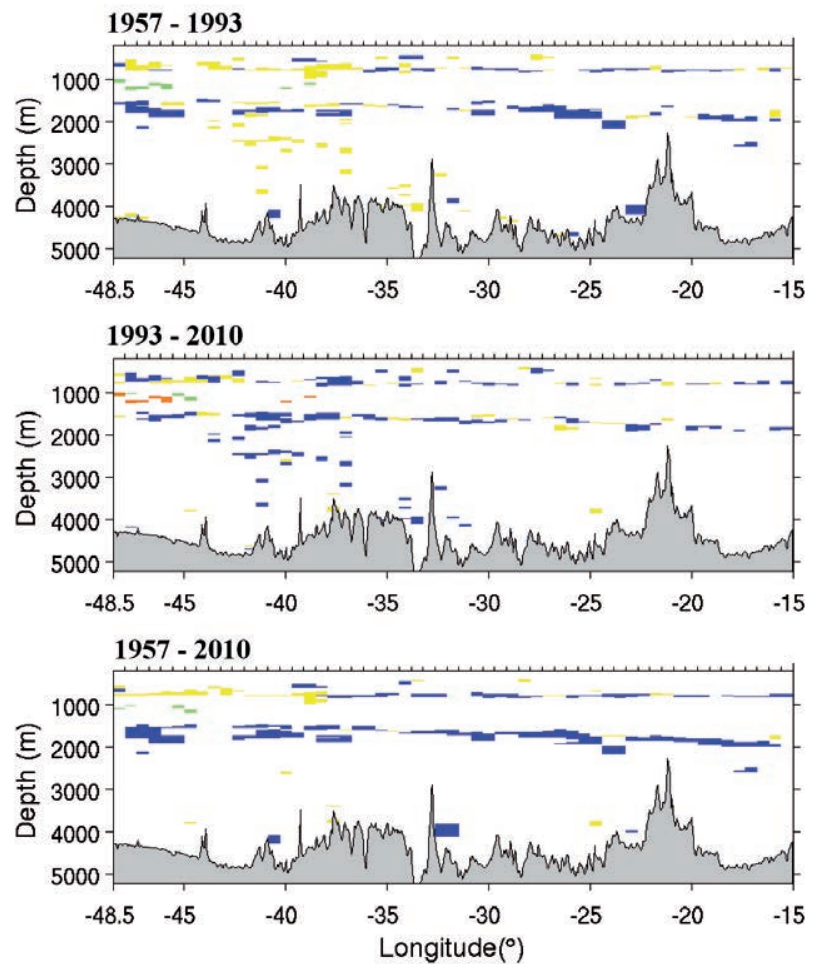

FIG. 9. - Inter-decadal variations of the Turner angle, $\Delta T u$ (Eq. 9), in the depth domain; the upper, middle and lower panels indicate changes for the periods 1957-1993, 1993-2010 and 1957-2010, respectively. The colour code reads as follows: blue indicates a transition from gravitational stability to salt-fingering; green, gravitational stability to diffusive convection; orange, diffusive convection to gravitational stability; yellow, salt-fingering to gravitational stability; the remaining possible transitions are left in white.

where the subindexes $f$ and $i$ respectively denote the final and initial states (Fig. 9). Some large values occur within deep waters, but these values are generally of opposite sign in the 1957-1993 and 1993-2010 periods, so the net 1957-2010 corresponding values are small; in fact, these changes appear to be linked to the relatively high patchiness that was present in the 1993 cruise (Fig. 7).

The largest absolute $\Delta T u$ values are linked to changes in the vertical extent of the AAIW and upper NADW strata: these are transitions from salt-fingering to gravitationally stable regimes and vice versa at depths ranges of about 500-1000 m and 1500-2000 m, respectively. The transition from gravitationally stable to salt-fingering regimes is clearly dominant, in particular between 1993 and 2010, effectively reducing the thickness of the gravitationally stable intermediate layers (Fig. 7). This transition is observed in both the upper and lower boundaries of the stable layer, though it is more evident for the lower boundary. The upper boundary exhibits some zonal differences, with a moderate reduction in the thickness of this stable layer in most of the section except on its westernmost margin (west of about $36^{\circ} \mathrm{W}$ to $40^{\circ} \mathrm{W}$, depending on the cruise). The major change, however, occurs in the lower boundary of the stable intermediate layer, be- tween the core of AAIW and the uppermost NADW. The observed variations in buoyancy frequency, with a substantial decrease in the density domain, are coherent with the changes in Turner angle, from stable to salt-fingering conditions.

\section{Is the 2010 distribution representative of neighbouring years?}

When using individual cruises to infer inter-decadal changes, we may reasonably wonder how representative one single measurement is for a certain period of time. In our case, with three single sections in a time span of 53 years, this question is of particular relevance. For an individual section to characterize a decadal period, the inter-decadal changes would have to be substantially greater than variations at shorter time scales. For a transatlantic section the potentially conflicting short time scales run from a few months, or seasonal, to inter-annual (much shorter time periods are not expected to significantly affect a transoceanic section). The causes for seasonal and inter-annual variations range from seasonal forcing, and the consequent horizontal and vertical propagation of the signal in the form of westward propagating Rossby waves (e.g. Brandt and Eden 2005), to inter-annual processes such as the North Atlantic Oscillation (e.g. Curry and McCartney 2001).

In order to address the above question we would require measurements in our region of interest at the seasonal and inter-annual scales. These are, certainly, not available for the 1957 and 1993 sections but the situation is much better for the 2010 cruise. The Argo globalarray of free drifting vertical profilers began in 2000 and in November 2007 reached its goal of simultaneously having over 3000 profilers in the global ocean, a number that has been maintained thereafter. Therefore, we may examine the consistency of the 2010 transatlantic data along $7.5^{\circ} \mathrm{N}$ with the available Argo measurements. The comparison can only cover the central, intermediate and upper deep waters, as most of the profilers in the Atlantic Ocean only sampled down to either 1500 or 2000 m; the original vertical resolution of the Argo profilers is 10 dbar but for this comparison, in order to remove the small-scale vertical variability, we will use the 50-dbar interpolated hydrographic and Argo data.

We here choose a very simple method to compare the Argo data set with the 2010 study across the tropical Atlantic. This consists in selecting two single stations from the 2010 cruise, one for the western margin (station 68 , located at $7.5^{\circ} \mathrm{N}, 43^{\circ} \mathrm{W}$ ) and one for the eastern margin (station 98 , located at $7.5^{\circ} \mathrm{N}, 25^{\circ} \mathrm{W}$ ), and to search for all Argo data available within some spatial and temporal search-window around these stations (only data flagged as good and not in the grey list were used). We recognize that it is a very simplified approach to a difficult problem, but it may provide a preliminary answer to the question of how representative the 2010 cruise is. 
After several tests with different spatial and temporal windows, we finally selected all Argo data from January 2003 to July 2011 and within a distance of $1^{\circ}$ from stations 68 and 98. In this manner a total of 55 and 111 profiles are respectively available for stations 68 and 98. In the two stations the temporal data distribution is quite homogeneous, although slightly biased towards summer months. The annual distribution is less uniform: in station 68 there were 42 profiles (out of 55) gathered between 2004 and 2006 while for station 98 there were 85 profiles (out of 111) gathered between 2008 and 2010.

The potential temperature-salinity diagrams illustrate that both hydrographic stations fall well within the corresponding cloud of Argo data points (top panels in Fig. 10). The vertical distribution of the neutral buoyancy frequency and Turner angle also show that the hydrographic stations conform to the variability displayed by the Argo data (middle and bottom panels in Fig. 10). In the case of the station 68 (left panels), these variables are depicted down to about $1400 \mathrm{~m}$, due to the sparse number of profiles below this depth.

The most important question, however, is how the differences between the 2010 data and the corresponding Argo data compare with the changes between the
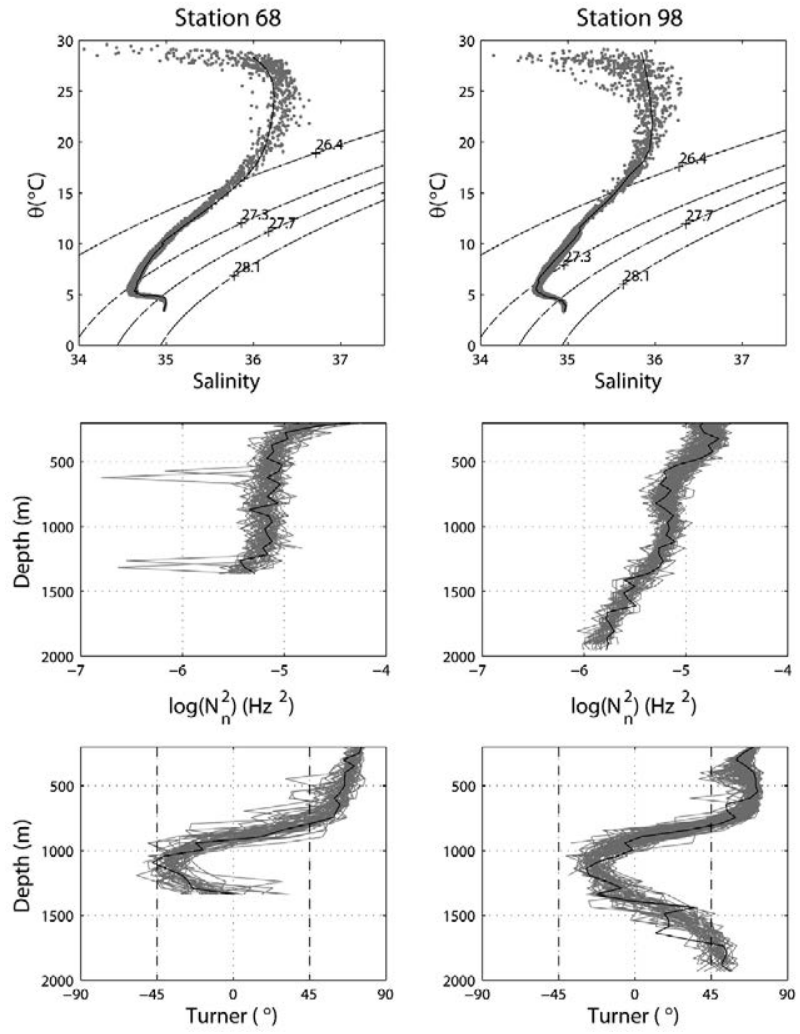

FIG. 10. - Hydrographic properties at stations $68\left(7.5^{\circ} \mathrm{N}, 43^{\circ} \mathrm{W}\right.$ left panels) and $98\left(7.5^{\circ} \mathrm{N}, 25^{\circ} \mathrm{W}\right.$; right panels) of the 2010 transect (black lines and points) and as obtained using all Argo floats data within $1^{\circ}$ of these same locations (grey lines and points). Theta-S diagram (upper panels), (middle panels) depth profiles of neutral buoyancy frequency, $\log \left(N_{n}^{2}\right)$, and (lower panels) depth profiles of Turner angle, $T u$.
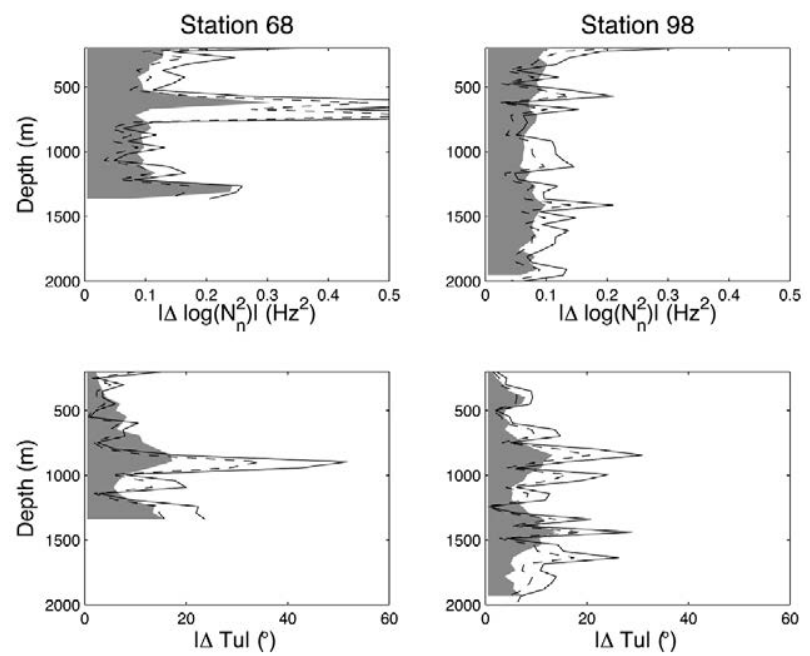

FIG. 11. - Variability in the absolute values of (upper panels) the neutral buoyancy frequency, $\log \left(N_{n}{ }^{2}\right)$, and (lower panels) the Turner angle, $T u$, as a function of depth for stations 68 (left panels) and 98 (right panels). Intra-decadal variations, indicated by shaded areas, are estimated as the one-standard deviation from the Argo data. The black curves represent the inter-decadal variations inferred from the mean (dashed) and maximum (solid) absolute difference between the hydrographic sections.

1957, 1993 and 2010 transatlantic sections. Figure 11 shows the one-standard deviation (for each depth level) of both $\log \left(N_{n}^{2}\right)$ (upper panels) and $T u$ (lower panels) as calculated using the Argo data. This one-standard deviation is expected to involve intra-decadal variations, i.e. only seasonal or inter-annual changes. These values may be compared with the mean and maximum absolute changes as inferred from the three sections (1957-1993, 1993-2010 and 1957-2010), which are assumed to characterize the inter-decadal variations. We observe that intra-decadal changes are slightly smaller than inter-decadal changes over most of the water column. A more thorough study would be required to separate seasonal from inter-annual changes and to assess how the latter are influenced by the fact that our Argo data set spans a total of 7.5 years (although at both stations most of the data pertains to a period of only three years), but this goes beyond our objectives. For our purposes it suffices to determine that the changes between cruises are, at least over most of the central and intermediate waters, significantly higher than the characteristic intra-decadal variations.

\section{Correlated $N_{n}^{2}$ and $T u$ changes}

In this section we turn to explore how the relationships between $N_{n}^{2}$ and $T u$ may have changed during the three transatlantic sections. In order to reduce the noise of the signal and improve the visualization of the predominant patterns, the variables represented in this subsection (Figs. 12 and 13) correspond to data interpolated every 50 dbar (pressure domain) or with density resolution increasing from 0.05 at $\gamma^{n}=26.65$ to 0.01 in deep waters (neutral-density domain). 

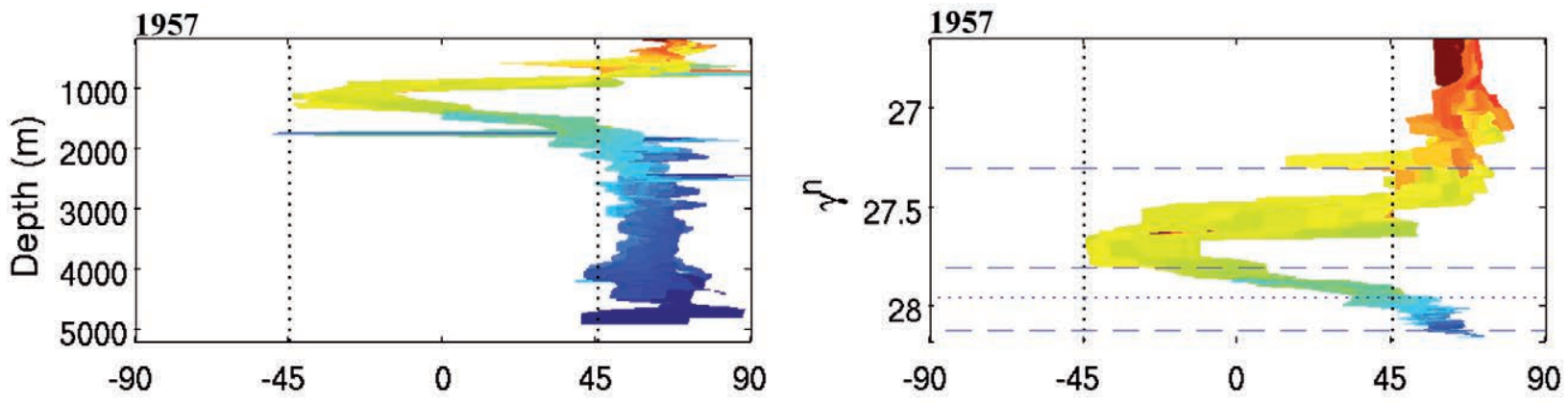

1993
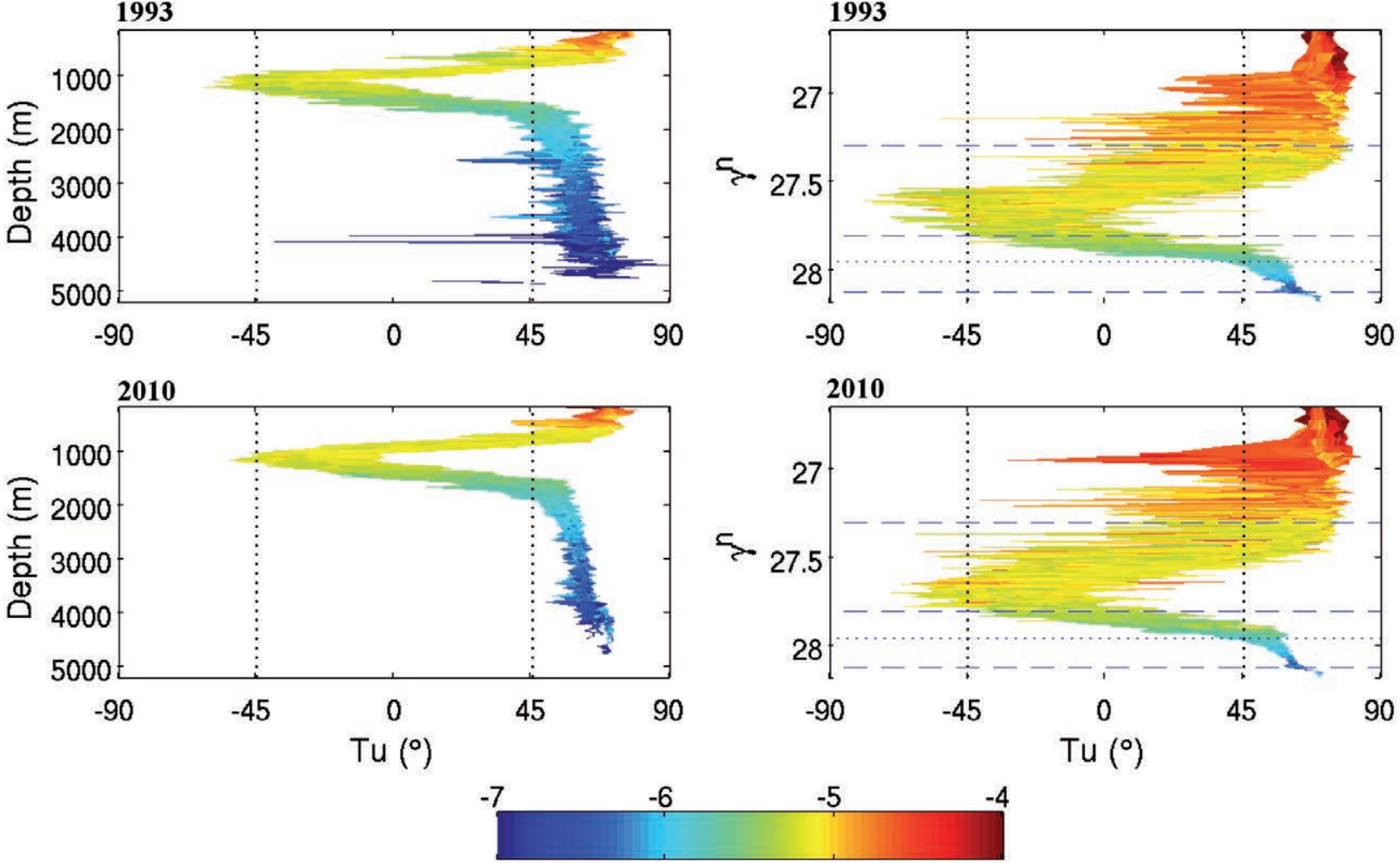

FIG. 12. - Neutral buoyancy frequency $\log \left(N_{n}^{2}\right)$ as a function of the Turner angle $T u$ represented in the depth and neutral density domains (left and right panels, respectively). The upper, middle and lower panels show the distributions for 1957, 1993 and 2010 cruises, respectively. The gravitationally stable region is located between the vertical dotted lines. The isoneutrals separating central, intermediate, deep and bottom waters $\left(\gamma^{n}=27.3,27.8\right.$ and 28.1) are dashed in blue while the isoneutral separating upper and middle deep waters $\left(\gamma^{n}=27.95\right)$ is dotted in blue.

In the depth domain (left panels of Fig. 12), we may appreciate how the gravitationally double-stable region approximately corresponds to $N_{n}^{2}$ values between $10^{-5}$ and $10^{-6} \mathrm{~s}^{-2}$; this range is equivalent to oscillation periods of the water parcels from 5 to 15 minutes. The representation in the neutral density domain (right panels of Fig. 12) shows that this doubly-stable region corresponds to intermediate and upper deep levels but also extends to some locations with $\gamma^{n}<27.3$, especially during the 1993 and 2010 studies. Stable points in central waters generally display $N_{n}^{2}$ values substantially smaller than in nearby densities prone to salt-fingering. Another important feature observed in the neutral density domain is the rising of the deepest stable points. We find that many stable points reached below $\gamma^{n}$ $=27.95$ in 1957 , whereas they rarely reached this level in 1993 and were almost absent in 2010 (see also right panels of Figure 8).

A plausible conclusion is that NADW has increased its presence with time and, as a consequence, the intermediate layer shrank. The increase of NADW may result from an intensification of the AMOC, at least in its upper deep waters; this has been suggested from observations throughout the North Atlantic (Marsh et al., 2005) and predicted by numerical models under the current scenario of global warming (Wunsch and Heimbach 2006), although it is still a source of controversy (e.g. Nilsson et al. 2003, Bryden et al. 2005). Cunningham et al. (2007) found substantial seasonal changes in the transport of upper NADW across $26.5^{\circ} \mathrm{N}$, with the southward transport getting intensified in fall, from some 10 to $15 \mathrm{~Sv}$. Therefore, since 
all three $7.5^{\circ} \mathrm{N}$ cruises were carried out in late winter or early springand because of the relatively moderate seasonal and inter-annual changes discussed in the previous section, it is plausible that the observed changes in NADW content are indeed related to inter-decadal variations.

In Figure 13 we show the zonally-averaged neutraldensity profiles as a function of depth for all three cruises. The upper left panel shows the whole profile, where the three data set appear to be very tight together. A closer inspection, however, confirms that there are significant variations. The upper-middle panel of Figure 13 zooms to the 300 to $1000 \mathrm{~m}$ depth range, which corresponds to the central and intermediate waters and contains the upper limit of the gravitationally stable layer seen in Figure 8. This zoom illustrates that, for a given $\gamma^{n}$ value, the three data set split away in the upper waters but tend to converge in the lower layers, with the 1957 and 2010 cruises respectively corresponding to the upper and lower limit. Therefore, the vertical density gradients were minimum and maximum in the 1957 and 2010 transects, respectively. The upper right panel of Figure 13 zooms to the 1800 to 2500 $m$ depth range, which corresponds to the upper part of the middle deep waters. The gradients are much lower than within the thermocline water but again we observe the same trend of temporal changes as in intermediate waters, now with most of the increase in stratification occurring between 1957 and 1993 .

The middle and bottom panels of Figure 13 also depict the absolute variations of $N_{n}^{2}$, in both the depth and neutral density, between 1993 and 2010 (middle panels) and between 1957 and 2010 (lower panels), colour-coded to illustrate the transitions between double diffusion and stability according to the changes in Turner angles. The zonally-averaged profile is shown on top of the whole range of variation for all data points. Let us first consider the neutral-density domain (right
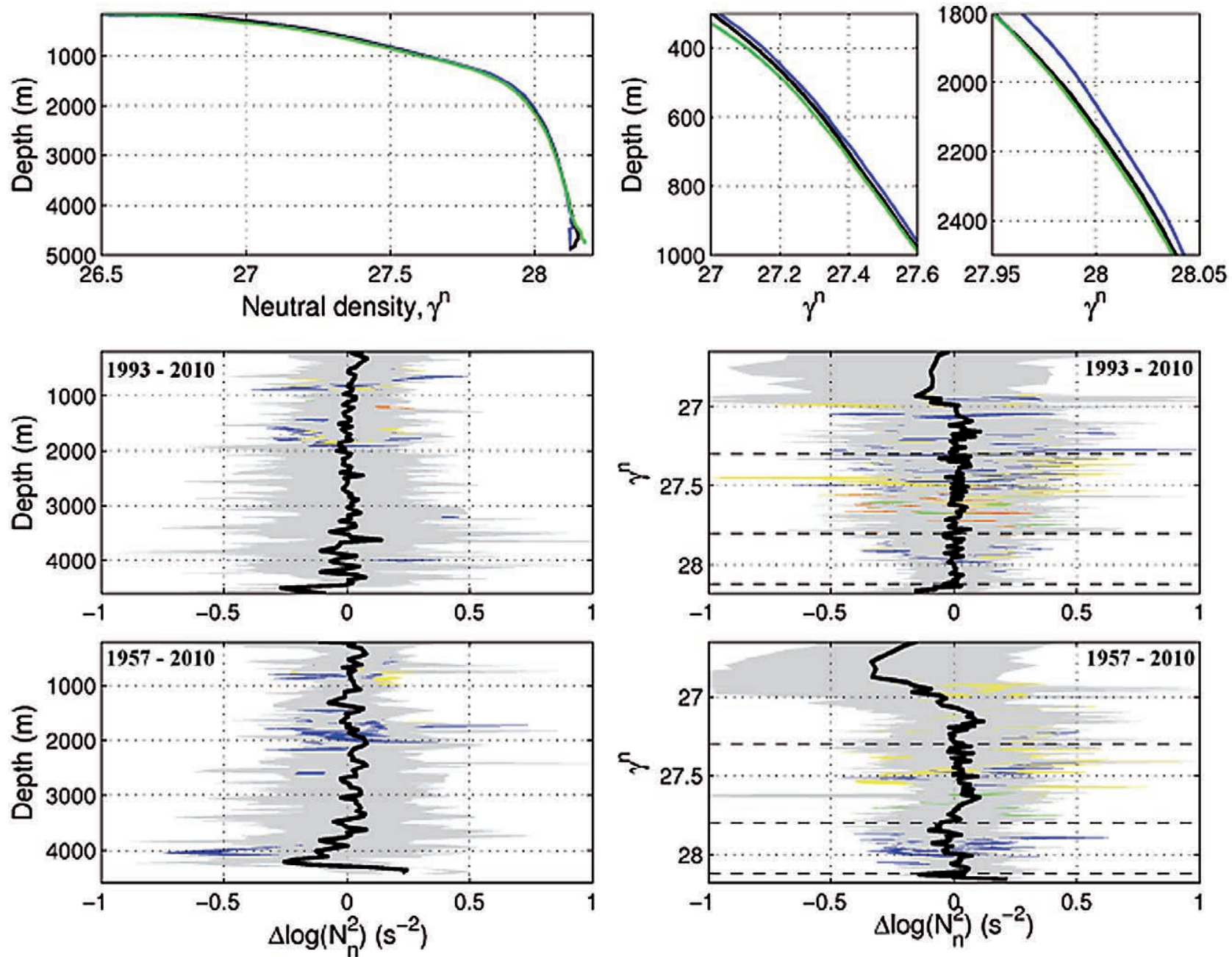

FIG. 13. - The upper panels show the zonally-averaged neutral density for the 1957 (blue), 1993 (black) and 2010 (green) transects. The middle and lower panels show the mean absolute variation of the squared neutral buoyancy frequency, $N_{n}^{2}$, calculated between 1993 and 2010 and between 1957 and 2010 (solid black lines), respectively, plotted on top of all values again coloured according to their Turner angle transitions in these periods (points are depicted in grey and the transitions are colour-coded as in Figure 9). The two left panels show the results in the depth domain, whereas the two right panels show the results in the neutral density domain. In the neutral density domain the levels $\gamma^{n}=27.3$, $27.8,28.1$ appear dashed in black. 
panels), i.e. changes associated with transitions in the water mass characteristics. Between 1957 and 1993 these changes were very small except for the upper central waters (densities less than 27.1) and the bottom waters (densities greater than 28.12). The stratification of the upper central waters decreased further between 1957 and 2010 but the change in bottom waters is less noticeable; additionally, during this same period the lower central waters (densities near 27.2) and central intermediate waters (densities near 27.6) had become more stratified and the lower intermediate and upper deep waters (densities just under 27.8) had turned into less stratified.

Let us now consider the depth domain, so that the changes also incorporate heaving effects (recall that in most of the water column, positive/negative contributions indicate sinking/raising of the isoneutrals). Between 1957 and 1993 the changes are very small everywhere except very close to the bottom. Between 1957 and 2010 the largest changes again correspond to near-bottom waters, with a decrease between about 4000 and $4500 \mathrm{~m}$ and an increase at greater depth; for the remainder of the water column the changes are much smaller but still substantially larger than for the 1993-2010 period. There are small increases near central waters $(500 \mathrm{~m})$, upper intermediate waters $(800 \mathrm{~m})$ and upper deep waters $(2000 \mathrm{~m})$ and the only noticeable decrease occurs in the central region of the intermediate waters (at about $1100 \mathrm{~m}$; recall the presence of a local stratification maximum at these depths, as seen in Figure 4, so the vertical gradient of the stratification changes sign). Therefore, the observed differences in the depth and density domains mainly serve to indicate the generalized sinking of all strata located between central and upper deep waters, in agreement with the changes visible in the top panels of Figure 13.

The subtle changes in the intermediate and surrounding waters from 1957 to 2010 may be appreciated with the help of a standard $\theta-S$ diagram (Fig. 14). All isoneutrals sank during this period but some of them did so by almost $100 \mathrm{~m}$ while others only were displaced a few metres. The maximum vertical displacements occurred within central and upper deep waters, while the minimum ones took place in the central intermediate waters (Fig. 14a). As a result of these differential motions, the lower central and upper intermediate layers became vertically compressed while the opposite happened within the lower intermediate and upper deep waters. The increased stratification observed near $800 \mathrm{~m}$ or about 27.4 (Fig. 14b), i.e. in upper intermediate waters, displays a mixture of changes between gravitational stability and salt-fingering, with no predominant trend (Fig. 14c). Within the lower intermediate and upper deep waters $\left(\gamma^{n}<27.8\right)$, in contrast, the stratification decreased (Fig. 14b) in association with major switches from gravitational stable towards saltfingering regimes (Fig. 14c). This change towards saltfingering strongly supports the idea that the less stratified NADW have reached shallower layers, formerly
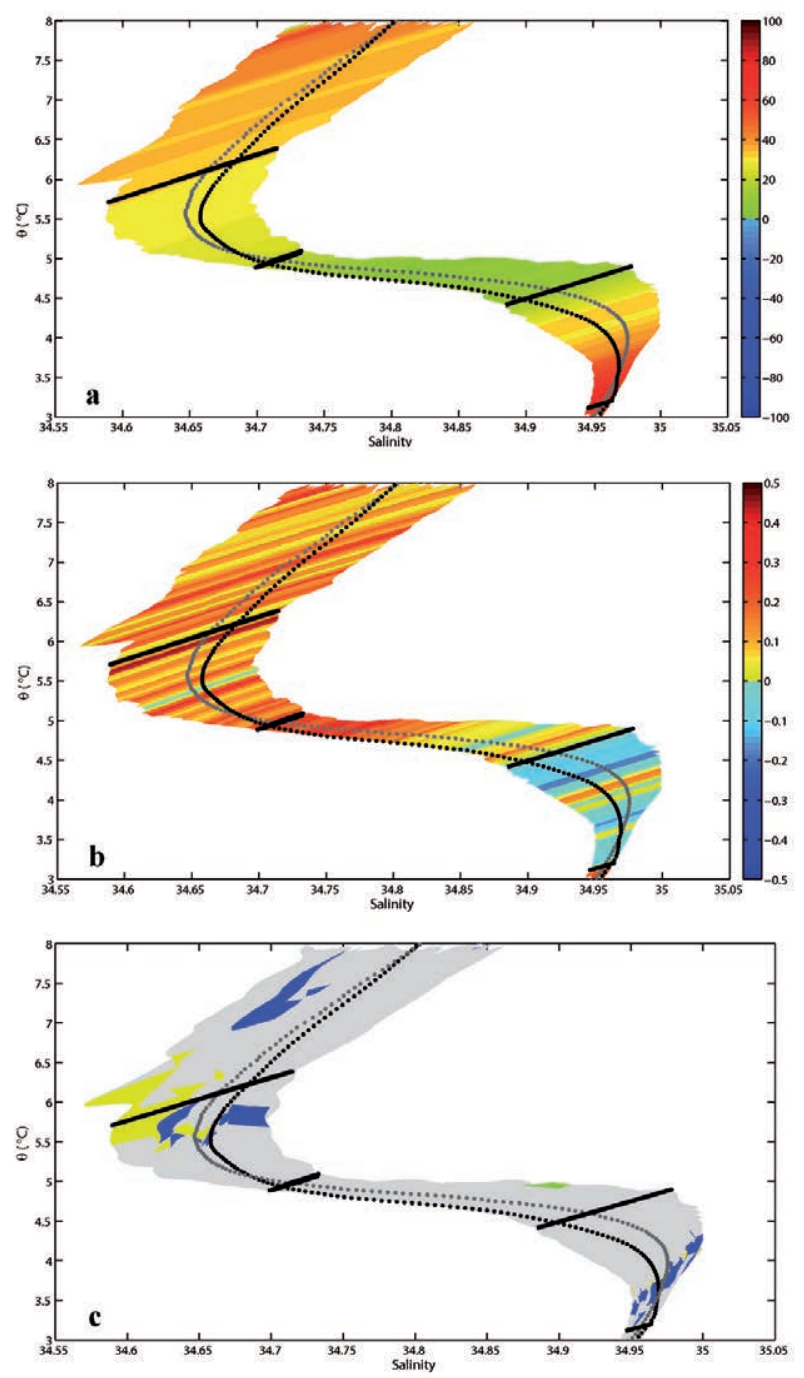

FIG. 14. - Potential temperature-salinity diagrams for intermediate and nearby waters, as produced with data from the 2010 transect (grey shaded). The black (1957) and grey (2010) dots correspond to the zonally-averaged temperature and salinity values on each isoneutral and the black solid lines correspond to $\gamma^{n}=27.2,27.4$, 27.6, 27.8. All values are calculated and represented in the neutral density domain. (a) Changes in the zonally-averaged depth of isoneutrals, positive/negative values denote sinking/rising of isoneutrals. (b) Relative changes in zonally-averaged neutral buoyancy frequency $\Delta N_{n}^{2}$ (Eq. 8). (c) Changes between gravitational and double-diffusive regimes, colour-coded as in Figure 9, plotted on top of the 2010 data.

found within intermediate waters. These variations are schematically illustrated in Figure 15.

\section{CONCLUSIONS}

Our objective was to investigate the long-term evolution of static stability along the $7.5^{\circ} \mathrm{N}$ transatlantic section through the analysis of the distributions of two quantities: buoyancy frequency and Turner angle. For this purpose we first explored whether the standard buoyancy frequency and Turner angle definitions may depend on the utilization of a distant reference pressure. Differences 

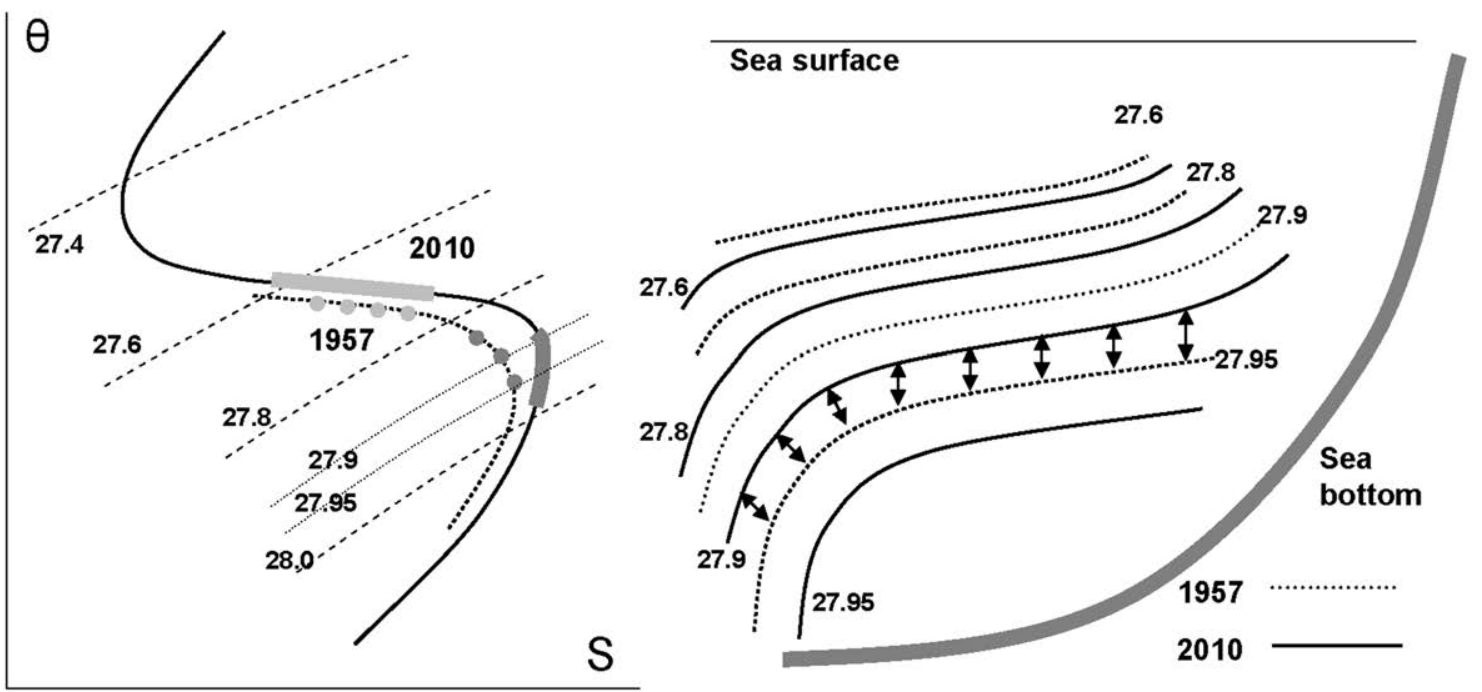

FIG. 15. - Schematics illustrating the stratification and heaving changes experienced between 1957 and 2010 within intermediate and upper deep layers. The left panel shows how the 1957 condition evolved towards the 2010 situation. The dark grey lines show the lower intermediate layers that evolved from stable into salt-fingering regimes; a similar situation would apply to the upper intermediate and lower central waters. The light grey lines illustrate the central intermediate layers which became more stratified in 2010 than in 1957 (the line covers a larger neutral-density interval). The right panel depicts the temporal transition of several selected isoneutrals within intermediate and upper deep waters: all isoneutrals sank in time but the stratification increased within the upper and central intermediate layers (not shown) and decreased within the lower intermediate and upper deep waters. Simultaneously some previously stable layers (above $\gamma^{n}=27.95$ in 1957) turned into layers prone to salt-fingering (below $\gamma^{n}=27.9$ in 2010, as denoted by the arrows) because of an enhanced presence of NADW.

TABLE 3. - Major temporal changes taking place from 1957 to 2010, between the lower central and upper deep waters (S-F, salt-fingering; EB, eastern basin; WB, western basin; CW, central waters; IW, intermediate waters; DW, deep waters).

\begin{tabular}{lcccc}
\hline water strata $\left(\gamma^{n}\right.$ range $)$ & heaving & $\begin{array}{c}\Delta N^{2} \\
\text { changes in water properties } \\
\left(\gamma^{n} \text { domain }\right)\end{array}$ & $\begin{array}{c}\text { added result } \\
(p \text { domain })\end{array}$ & $\begin{array}{c}\Delta T u \\
\text { result } \\
(p \text { domain })\end{array}$ \\
\hline $\begin{array}{l}\text { lower CW } \\
(<27.3)\end{array}$ & $\begin{array}{c}\text { increase } \\
\left(\gamma^{n} \text { sink }\right)\end{array}$ & moderate increase & increase & $\begin{array}{c}\text { large S-F increase in EB; } \\
\text { moderate S-F decrease in WB }\end{array}$ \\
$\begin{array}{l}\text { upper and central IW } \\
(27.3-27.7)\end{array}$ & $\begin{array}{c}\text { decrease } \\
\left(\gamma^{n} \text { sink as } \partial N^{2} / \partial p<0\right)\end{array}$ & increase & small changes \\
$\begin{array}{l}\text { lower IW and upper DW } \\
(27.7-27.95)\end{array}$ & $\begin{array}{l}\text { increase } \\
\left(\gamma^{n} \text { sink }\right)\end{array}$ & (NADW reaches shallower levels $)$ & small changes & large S-F increase \\
\hline
\end{tabular}

between the standard buoyancy frequency definition (referenced to the sea surface) and an alternative definition (neutral buoyancy frequency, which uses neutral density rather than potential density) are practically negligible for the thermocline waters (approximately the top $1000 \mathrm{~m}$ depth) but become appreciable for deep waters, with the neutral buoyancy frequency having less variability and values slightly smaller than the buoyancy frequency. We repeated this exercise for the Turner angle, exploring a modified definition with potential temperature referred to a varying pressure level. In this case the differences are very small and it is the conventional Tu definition which displays least variability within deep waters. On the basis of these results we chose the conventional Turner angle definition and the modified neutral buoyancy frequency for all subsequent analyses.

The distributions of neutral buoyancy frequency and Turner angle were examined in both depth and neutral density spaces for all three $7.5^{\circ} \mathrm{N}$ transatlantic sections, i.e. the historical 1957 and 1993 and the recent 2010 transect. The utilization of both depth and neutral-density domains gives best resolution in the deep and upper waters, respectively, and primarily allows us to identify the changes that are associated with modified water characteristics and those that are related to heaving of isoneutrals. The analysis ignored the near-surface waters, which are subject to seasonal variations, specifically waters shallower than $200 \mathrm{~m}$ or approximately lighter than neutral density $\gamma^{n}=26.65$.

The distributions of the two properties highlight the vertical and zonal variations of the equatorial Atlantic. The vertical distributions reflect the successive strata of SACW, AAIW, NADW and AABW. The major zonal changes take place within central and intermediate waters, with greater stratification and more presence of AAIW in the western basin. The Turner angle reveals the predominance of salt-fingering processes, resulting from the unstable salt distribution in the North Atlan- 
tic. A gravitationally doubly-stable layer, related to the presence of the relatively fresh intermediate waters, is observed between about $800 \mathrm{~m}$ and $1500-2000 \mathrm{~m}$, thickening eastwards.

One very important issue of our analysis is whether we can consider the changes between the three different cruises as representative of long-term or inter-decadal variations. For this to be true the variations have to be substantially larger than the seasonal or inter-annual changes, which we assess using Argo data from 2003 to 2011. Our analysis shows that the measurements during the 2010 transect conform to the Argo variability in central and intermediate waters, and that the changes observed between cruises are generally greater than the intra-decadal changes derived from the onestandard deviation of the Argo data set. This grants us good confidence that the calculated variations between the three sections are likely to be representative of the inter-decadal changes, although a more exhaustive investigation is still necessary to confirm this idea.

The comparison of all three distributions allows us to identify the existence of major variations in the buoyancy frequency in both neutral-density and depth representations. In the density representation, only intermediate ( $13 \%$ increase) and upper deep (6\% decrease) waters display changes significantly different from zero; central and bottom waters also experience large increases but smaller than the onestandard deviation values. In the depth representation the significant changes (always an increase) occur for central $(15 \%)$, intermediate $(7 \%)$ and middle deep (14\%) waters, while the upper deep waters are not significantly different from zero. Therefore, central, upper deep and middle deep waters make quite a large positive contribution due to sinking of the isoneutrals, while intermediate waters make a moderate negative contribution, also associated with the sinking of isoneutrals (recall that $\partial N^{2} / \partial p$ changes sign within intermediate waters).

These results suggest that the position of the (increasingly stratified) stratum between central and intermediate waters has not changed much and also support the view that the (increasingly unstratified) stratum between the intermediate and upper deep waters has moved up, with a net thinning of the intermediate stratum. Indeed, the temporal variation of the Turner angle highlights an enhancement of the region prone to salt-fingering processes, related to the narrowing of the doubly-stable gravitational layer. The top of this stable layer shallows on the western margin and sinks on the eastern margin, while the bottom of the stable layer clearly shallows throughout the whole section. The net result is a decrease in the contribution of AAIW and an increased presence of NADW. In summary, the main features of the nearintermediate waters are (1) a differential sinking of isoneutrals with minimum drop values in the central intermediate waters, (2) an enhancement of saltfingering in the lower central and upper intermediate waters, associated with an increase in stratification, and (3) an increased presence of upper deep waters reaching shallower isoneutrals. Table 3 summarizes some of these ideas and Figure 15 illustrates the ongoing major transitions in the lower intermediate and upper deep water strata.

Although increased stratification implies a more stable ocean and less nutrient supply to the surface layers (Steinacher et al. 2010), our results suggest that in some instances it is accompanied by an increase in double diffusion, with an opposing effect on the intensity of vertical diffusion. The origin of such changes may be related to the existence of inter-decadal variations in the different components of the water column, in our case possibly with an intensified NADW flow and a weakened AAIW presence; the existence of analogous compensating changes in the different AMOC components, at seasonal time scales, has recently been reported by Kanzow et al. (2011). Further data and additional studies are required to determine whether some of the observations are related to seasonal or inter-annual oscillations in the central and intermediate waters, and to properly quantify the mixing scenario in a highly stratified salt-fingering upper ocean.

\section{ACKNOWLEDGEMENTS}

This research was supported by the Spanish National R\&D Plan, in the framework of projects MOC2 (CTM2008-06438-C02-01) and TIC-MOC (CTM2011-28867). The authors are grateful to the BIO Hespérides scientists, technicians and crew for making it possible to gather the 2010 data set. Special thanks go to the chief technician, José Antonio Pozo, and to Mikhail Emelianov, Eugenio Fraile, Jesús Peña, Marc Gasser and Miquel Rosell. We are also grateful to our reviewers for many useful comments and suggestions. Finally, the first author is indebted to Adrián San Antolín, Beatriz Herrero, Miguel Ángel San Antolín Casado and María Concepción Plaza for their continuous support.

\section{REFERENCES}

Arhan M., Mercier H., Bourles B., Gouriou Y. 1998. Hydrographic sections across the Atlantic at $7^{\circ} 30 \mathrm{~N}$ and $4^{\circ} 30 \mathrm{~S}$. Deep-Sea Res. Part I 45: 829-872.

Bindoff N.L., McDougall T.J. 1994. Diagnosing climate-change and ocean ventilation using hydrographic data. J. Phys. Oceanogr. 24: 1137-1152.

Brandt P., Eden C. 2005. Annual cycle and interannual variability of the mid-depth tropical Atlantic Ocean. Deep-Sea Res. Part I 52: 199-219.

Bryden H.L., Longworth H.R., Cunningham S.A. 2005. Slowing of the Atlantic meridional overturning circulation at $25^{\circ}$ N. Nature 435(7068): 655-657.

Cunningham S.A., Kanzow T., Rayner D., Baringer M.O., Johns W.E., Marotzke J., Longworth H.R., Grant E.M., Hirschi J.J.M., Beal L.M., Meinen C.S., Bryden H.L. 2007. Temporal Variability of the Atlantic Meridional Overturning Circulation at $26.5^{\circ}$ N. Science 317(5840): 935-938.

Curry R.G., McCartney M.S. 2001. Ocean gyre circulation changes associated with the North Atlantic Oscillation. J. Phys. Ocea- 
nogr. 12: 3374-3400.

Fuglister F.L. 1960. Atlantic Ocean Atlas of Temperature and Salinity Profiles and Data from the International Geophysical Year of 1957-1958. Atlas Series, Woods Hole Oceanographic Institution, Vol. 1.

Ganachaud A. 2003. Large-scale mass transports, water mass formation, and diffusivities estimated from World Ocean Circulation Experiment (WOCE) hydrographic data. J. Geophys. Res 108: 3213.

Jackett T.R., McDougall T.J. 1997. A neutral density variable for the world's ocean. J. Phys. Oceanogr. 27: 237-263.

Kanzow T., Cunningham S.A., Rayner R., Hirschi J.J.M., Johns W.E., Baringer M.O., Bryden H.L., Beal L.M., Meinen C.S., Marotzke J. 2011. Observed flow compensation associated with the MOC at $26.5^{\circ} \mathrm{N}$ in the Atlantic. Science $317(5840)$ : 938-941.

Lappo S.S., Lozovatsky I.D., Morozov E.G., Sokov A.V., Shapovalov S.M. 2001. Variability of water structure in the Equatorial Atlantic. Dokl.-Earth Sci. Sect. 379: 739-743.

Lozier M.S., Owens W.B., Curry R. 1995. The climatology of the North Atlantic. Prog. Oceanogr. 36: 1-44.

Lux M., Mercier H., Arhan M. 2001. Interhemispheric exchanges of mass and heat in the Atlantic Ocean in January-March 1993. Deep-Sea Res. Part I 48: 605-638.

Marin F., Gouriou Y. 2000. Heat fluxes across $7^{\circ} 30^{\prime} \mathrm{N}$ and $4^{\circ} 30^{\prime} \mathrm{S}$ in the Atlantic Ocean. Deep-Sea Res. Part I 47: 2111-2139.

Marsh R., de Cuevas B.A., Coward A.C., Bryden H.L., Alvarez M. 2005. Thermohaline circulation at three key sections in the North Atlantic over 1985-2002. Geophys. Res. Lett. 32: L10604.

McDougall T.J. 1987. Neutral surfaces. J. Phys, Oceanogr. 17: 1950-1964.

Oudot C., Morin P., Baurand F., Wafar M., Le Corre P. 1998. Northern and southern water masses in the equatorial Atlantic: distribution of nutrients on the WOCE A6 and A7 lines. Deep-
Sea Res. Part I 45: 873-902.

Ruddick B. 1983. A practical indicator of the stability of the water column to double-diffusive activity. Deep-Sea Res. 30: 1105-1107.

Ruddick B., Gargett A.E. 2003. Oceanic double-diffusion: introduction. Prog. Oceanogr. 56: 381-393.

Schmitt R.W., Perkins H., Boyd J.D., Stalcup M.C. 1987. C-Salt: An investigation of the thermohaline staircase in the western tropical North Atlantic. Deep-Sea Res. Part A 34: 1655-1665.

Schmitt R.W., Ledwell J.R., Montgomery E.T., Polzin K.L., Toole J.M. 2005. Enhanced diapycnal mixing by salt fingers in the thermocline of the Tropical Atlantic. Science 308: 685-688.

Schott F.A., McCreary J.P., Johnson G.C. 2004. Shallow overturning circulations of the tropical-subtropical oceans. In: Wang C., Xie S.-P., Carton J.A. (eds.), Earth Climate: The Ocean-Atmosphere Interaction. AGU Geophys. Monogr. Ser. 147: 261-304.

Steinacher M., Joos F., Frölicher T.L., Boop L., Cadule P., Cocco V., Doney S.C., Gehlen M., Lindsay K., Moore J.K., Schneider B., Segschneider J. 2010. Projected 21st century decrease in marine productivity: a multi-model analysis. Biogeosciences 7: 979-1005.

Stramma L., Schott F. 1999. The mean flow field of the tropical Atlantic Ocean. Deep-Sea Res. Part II 46: 279-303.

Thorpe S.A. 1977. Turbulence and Mixing in a Scottish Loch. Phil. Trans. Roy. Soc. London A 286: 125-181.

Wunsch C., Heimbach P. 2006. Estimated Decadal Changes in the North Atlantic Meridional Overturning Circulation and Heat Flux 1993-2004. J. Phys. Oceanogr. 36: 2012-2024.

You Y. 2002. A global ocean climatological atlas of the Turner angle: implications for double-diffusion and water-mass structure. Deep-Sea Res. Part I 49: 2075-2093.

Received March 2, 2011. Accepted January 17, 2012.

Published online August 6, 2012. 